\title{
WestVirginiaUniversity
}

THE RESEARCH REPOSITORY @ WVU

Graduate Theses, Dissertations, and Problem Reports

2010

\section{The development of a dynamic scissor lift model}

Jared J. Hartsell

West Virginia University

Follow this and additional works at: https://researchrepository.wvu.edu/etd

\section{Recommended Citation}

Hartsell, Jared J., "The development of a dynamic scissor lift model" (2010). Graduate Theses,

Dissertations, and Problem Reports. 2149.

https://researchrepository.wvu.edu/etd/2149

This Thesis is protected by copyright and/or related rights. It has been brought to you by the The Research Repository @ WVU with permission from the rights-holder(s). You are free to use this Thesis in any way that is permitted by the copyright and related rights legislation that applies to your use. For other uses you must obtain permission from the rights-holder(s) directly, unless additional rights are indicated by a Creative Commons license in the record and/ or on the work itself. This Thesis has been accepted for inclusion in WVU Graduate Theses, Dissertations, and Problem Reports collection by an authorized administrator of The Research Repository @ WVU. For more information, please contact researchrepository@mail.wvu.edu. 
The Development of a Dynamic Scissor Lift Model

\title{
Jared J. Hartsell
}

\author{
Thesis submitted to the \\ College of Engineering and Mineral Resources \\ at West Virginia University \\ in partial fulfillment of the requirements \\ for the degree of \\ Master of Science \\ in \\ Mechanical Engineering
}
Kenneth Means, Ph.D., Chair
Victor Mucino, Ph.D. Ren Dong, Ph.D.

Department of Mechanical and Aerospace Engineering

\author{
Morgantown, West Virginia \\ 2010
}

Keywords: Scissor lift, modeling, ADAMS $^{\circledR}$ 


\section{ABSTRACT \\ The Development of a Dynamic Scissor Lift Model}

\section{Jared J. Hartsell}

Tip-over/rollovers are the most frequent cause of fatalities associated with the use of scissor lifts. The objective of this study is to develop a dynamic model of a scissor lift to investigate tip-overs. A multibody dynamic model of a typical scissor lift was created using an advanced modeling platform - ADAMS ${ }^{\circledR}$. This model was statically validated and dynamically calibrated based on experimental results from center of gravity, curb impact, and pothole depression tests. The dynamic responses of the scissor lift model were consistent with the experimental data. Once calibrated/validated, the model was used to simulate hazardous scenarios while varying the scissor lift's flexibility. Results of the simulations indicate that increased flexibility reduces the scissor lift's stability. This developed scissor lift model could be used to perform additional simulated conditions and for design optimization. 
Title Page

$\begin{array}{ll}\text { Abstract } & \text { ii }\end{array}$

Table of Contents $\quad$ iii

Figures Listed $\quad$ V

Tables Listed vii

Acknowledgements viii

1.0 Introduction 1

1.1 Background 1

1.2 Proposed Dynamic Scissor Lift Model 3

2.0 Literature Review 4

2.1 Current Standards $\quad 4$

2.2 Studies Related to MEWP Stability 6

2.4 Overview of ADAMS

2.5 Applications of ADAMS $\quad 8$

3.0 Method 10

3.1 Examined Scissor Lift 10

3.2 Experiments 11

3.3 Modeling Overview 14

3.4 Rigid Body Construction $\quad 19$

3.5 Kinematic Constraints 21

3.6 Contacts and Connections 24

3.7 Solution of the Equations of Motion $\quad 29$

3.8 Simulations $\quad 32$

4.0 Results 36

4.1 Model Calibration/Validation 36

4.2 Tilting Rollover Threshold $\quad 42$

4.3 Lateral Force Rollover Threshold $\quad 43$

4.4 Curb Impact Speed Tip-over Threshold 44

4.5 Rollover Threshold based on Pothole Protection Device Height 46

4.6 Instability due to Fall Arrest Forces $\quad 48$

$\begin{array}{ll}5.0 \text { Conclusion } & 50\end{array}$

6.0 Future Work $\quad 51$ 
7.0 References 


\section{Figures Listed}

Fig. 1: Examined scissor lift

Fig. 2: A pictorial view of the tested scissor lift and the experimental site

Fig. 3: Experimental manikin drop test

Fig. 4: Scissor lift model with identified parts

Fig. 5: Scissor lift model with identified constraints $(\Delta)$, and connections/contacts $(\square)$

Fig. 6: Actuator assembly with identified parts (०), joints $(\Delta)$, and connections $(\square)$

Fig. 7: Piston motion as described by a ramp function

Fig. 8: Illustration of impact (MSC Software Corporation)

Fig. 9: Two-dimensional diagram of inner scissor frame 1

Fig. 10: Measured load cell data from manikin drop tests: (a) $1.83 \mathrm{~m}$ drop height (b) $3.35 \mathrm{~m}$ drop height

Fig. 11: Comparison of the measured accelerations on the main platform (left column) with those predicted from the modeling (right column) for a standardized direct curb impact test.

Fig. 12: Comparison of the measured accelerations on the main platform (in the left column) with those predicted from the model (in the right column) for the standardized pothole depression test.

Fig. 13: Tilt table simulation

Fig. 14: Effect of the scissor lift structure stiffness on the tilting rollover threshold

Fig. 15: Lateral force simulation

Fig. 16: Effect of the scissor lift's structure stiffness on the rollover threshold due to a lateral force applied to the guardrail.

Fig. 17: Simulated curb impact

Fig. 18: Effect of the scissor lift structure's stiffness on the tip-over threshold for a curb impact 
Fig. 19: Simulated pothole depression test

Fig. 20: Effect of the scissor lift structure stiffness on the rollover threshold of the pothole protection device height measured from the ground.

Fig. 21: Fall arrest force simulation

Fig. 22: Effect of the scissor lift structure stiffness on the rear wheel lifting height due to fall arrest forces

Fig. 23: Merging biodynamic model with scissor lift model 


\section{Tables Listed}

Table 1: Global coordinates of the center of mass (CM) of the lumped parts in the scissor lift model at stowed position (without static equilibrium) and their mass properties ( $m$ - mass; $I x$ - moment of inertia around $X$-axis; $I y$ - moment of inertia around $Y$-axis; $I z$ - moment of inertia around $Z$-axis).

Table 2: Kinematic joints of the scissor lift model

Table 3: Algebraic kinematic constraint equations (MSC Software Corp.)

Table 4: Allowable degrees of freedom for model

Table 5: Major flexible connections and their major parameters

Table 6: Comparison of the center of gravity (CG) of the scissor lift model and that measured in an experiment (Ronaghi et al., 2009). 


\section{Acknowledgements}

I would like to acknowledge several people who have made this thesis possible. First, I would like to thank Dr. Kenneth Means for his role as my advisor. His willingness to provide technical expertise and support is greatly appreciated. Dr. Ren Dong was extremely helpful in the model development stage and I found his enthusiasm to be inspiring. Also, I would thank Dr. Victor Mucino for his constructive comments on the project. Appreciation is due to Dr. Christopher Pan for giving me the opportunity to work on the aerial lift project. Special thanks to my girlfriend, Jessica, for giving me the guidance to complete graduate school. Finally, I would like to thank my parents for their support throughout my life. 


\section{Chapter 1: Introduction}

\subsection{Background}

A scissor lift is a type of mobile elevating work platform (MEWP). In comparison to other forms MEWPs such as booms lifts, scissor lifts can easily be maneuvered in confined spaces. As a result, scissor lifts are widely used indoor and outdoor in construction, telecommunications, and other industries. The primary purpose of a scissor lift is to elevate workers with their tools and materials, while providing a working platform. Unlike boom lifts, the working platform of a scissor lift cannot be horizontally positioned beyond the base (Burkart et al., 2004). Since the platform can be raised or lowered to the optimal working height, the physical demands of the worker can be reduced. The elevated heights of scissor lifts vary, with larger models achieving heights

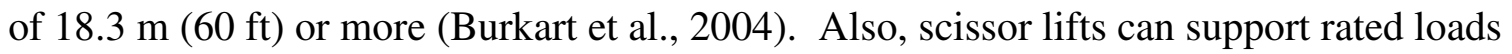
up to $1134 \mathrm{~kg}(2500 \mathrm{lbs})$.

Due to an increase in worker productivity, the demand for scissor lifts grew throughout the '90s, with sales of around 20,000 units per year in the mid-'90s to a peak of 50,000 units in 2000 (Yengst, 2002). Since peak production in 2000, scissor lift sales have fluctuated. The sales are heavily influenced by the rental equipment industry, which is the number one buyer of aerial work platforms (Yengst, 2005). The sale of scissor lifts in 2004 was projected to be over 27,000 units (Yengst, 2005).

As scissor lifts have become increasingly popular, fatal and non-fatal incidents have occurred. Based on the Census of Fatal Occupational Injuries (CFOI) data, 78 scissor lift fatalities occurred between 1992 and 2003 (Pan et al., 2007). Of these fatalities, 74\% occurred in the construction industry. Fatalities associated with scissor lift use have 
numerous causes such as: falls from lifts, electrocutions, struck by objects, and scissor lift tip-overs/rollovers (Pan et al., 2007; McCann, 2003). However, scissor lift tipover/collapse has been the most common event resulting in these incidents (Pan et al., 2007; Knoll, 2002). Most often, these tip-overs occur while the lift is elevated to heights in the range of 10-29 feet (Pan et al., 2007). The contributing factors for scissor lift tipover include: mechanical failure, lift motion, surface condition, overloading, and operator misuse to name a few (Pan 2007 et al., 2007; Knoll, 2002). While many of these incidents could be prevented by adhering to the operator's manual, training programs, and proper lift maintenance, further studies are necessary to better understand the instability of scissor lifts from an engineering control prospective. These studies may also lead to advances in the educational material and training programs.

Currently, a standard developed by the International Organization for Standardization (ISO 16368, 2003) defines the design calculations, technical safety requirements, and test methods for MEWP. Similarly, the American National Standard Institute (ANSI) provides a standard (ANSI A92.6, 2006) with criteria for design, manufacture, testing, and operation of self-propelled elevating work platforms. Since the MEWPs are generally considered rigid body structures in the design calculations of ISO 16368, it is unknown whether these standardized assessments are adequate in predicting tip-over thresholds. Identified dynamic forces are often treated as static loads with multiplier factors in the standard's overturning moment calculations of ISO 16368. While ISO 16368 has suggested typical forces to be considered, the combined dynamic effects of these forces are difficult to account for using a static rigid body model. The elasticity of structures, clearances in joints, and flexibility of the hydraulic actuator affect the rigidity 
of a scissor lift. The resulting flexibility of the scissor lift could significantly affect its stability. With continued use, the flexibility of the lift could increase as a result of wear in the joints of the scissor lift. Therefore, further analysis is needed to better understand these effects on the safety margins and instability of scissor lifts.

\subsection{Proposed Dynamic Scissor Lift Model}

The purpose of this study was to develop a dynamic model of a typical scissor lift using an advanced modeling platform- ADAMS®, Version 2008r1 (MSC Software Corporation, Santa Ana, CA). This lumped parameter model was developed using the manufacturer's drawings for a popular, compact scissor lift. In order to validate the mass distribution of the model, the measured center of gravity $(\mathrm{CG})$ position at various lifting heights were used (Ronaghi et al., 2009). The stiffness and damping of certain connections were estimated based the results of experimental curb impact and pothole depression tests. Dynamic calibration of the scissor lift model was achieved by comparison of the simulated response with the experimental response of these tests. Once the model was calibrated/validated, the influence of flexibility on scissor lift instability was examined by simulating various static and dynamic scenarios. For the static scenarios, the rollover thresholds were predicted for an applied lateral force and a sloped ground condition. Dynamic tip-over thresholds were determined for simulated curb impact and pothole depression tests. Last, the instability of the scissor lift due to fall arrest forces, obtained from experimental manikin drop tests, was examined. 


\section{Chapter 2: Literature Review}

\subsection{Current Standards}

In order to protect workers from accidents regarding the use of MEWPs, standards have been developed. With respect to scissor lift stability, two standards have been developed. The International Organization for Standardization (ISO) standard (ISO 16368, 2003) and American National Standards Institute (ANSI) standard (ANSI/SIA A92.6, 2006) provide design, manufacturing, testing, and safety requirements for scissor lifts. The physical tests in these standards are to be performed on a new unit of a particular scissor lift model. For the static tests, ISO 16368 specifies the scissor lift be subjected to a combination of loads and forces while at its most unfavorable position. Loads and forces to be considered include: rated load, wind forces, manual forces, and other forces determined by the manufacturer. ANSI A92.6 requires manufacturers to perform a horizontal load test, vertical load test, and a static load test on sloped ground. With regard to dynamic tests, both standards specify a curb impact test and a depression test. The curb impact test involves driving the scissor lift into a standardized curb at maximum speed. Similarly, the depression test requires the scissor lift to be driven into a standardized square pothole at maximum speed. For all test conditions, the scissor lift is considered stable if tip-over/rollover does not occur.

In addition to physical tests, ISO 16368 requires manufacturers to perform stability calculations. The same loads and forces considered in the physical tests are analyzed in the static stability calculations. In order to account for dynamic effects, forces produced by acceleration/deceleration for the curb impact test are treated as a dynamic multiplier factor. The standard also specifies that tolerances in component manufacture, clearances 
in joints, and elastic deformations are considered in the stability calculations. However, the method in which these variables are accounted for is not specifically defined. A method for predicting the tip-over speed in a curb impact is provided in ISO 16368. This calculation is based on the conservation of energy is defined by the following:

$$
\begin{aligned}
& \text { K.E. }=\frac{1}{2} m v^{2} \\
& P . E .=m g \Delta z
\end{aligned}
$$

where:

- $m$ is mass of the lift

- $v$ is the speed of lift

- $\mathrm{g}$ is gravitational constant

- $\Delta z$ is the change in height of lift's center of gravity position

If the potential energy (P.E.) after impact is greater than the kinetic energy (K.E.) prior to impact, then tip-over will occur. Using this method, only the gravitational potential energy is considered. In reality, the scissor lift exhibits some flexibility from clearances in joints and elasticity of the frame members, which could affect the tip-over speed threshold.

While these standards are quite extensive in their test methods, additional hazardous scenarios may lead to tip-over/rollover. The ground surface under the lift's tires may soften, resulting in the tilting of the lift. Human interactions with the lift could produce instabilities but physically testing these conditions would be too dangerous. If not properly maintained, the bearings and joints of a scissor lift could wear. It is unknown whether the increased flexibility from this wear could affect the lift's stability. The use of dynamic simulation model may lead to a better understanding of scissor lift stability. 


\subsection{Studies Related to MEWP Stability}

Multibody dynamic models have been extensively used to examine the tipover/rollover scenarios of automobiles, buses, trains, etc. However, few studies have been performed on the tip-over/rollover stability of scissor lifts. A scissor lift dynamic simulation model was developed and used to evaluate its static stability under an applied force (Ronaghi et al., 2009). It was determined from this study that scissor lift tip-over could occur from a pushing or pulling force applied by a worker. Although the model's center of gravity (CG) position was validated with experimental data, dynamic characteristics of the scissor lift model were not considered. Since the proposed model was assumed to be a perfectly rigid system, the study did not address the effects of flexibility on its stability. Also, the instability of the scissor lift under dynamic conditions was not considered in the simulations.

A three-dimensional simulation model of a manipulator-like mobile hydraulic machine (boom lift) has been developed (Abo-Shanab and Sepehri, 2005). This model accounted for flexibility between the base of the lift and ground surface. It was determined that increasing the stiffness between the base and ground improved the machine's stability. While not as influential as the system's stiffness, increased damping also provided additional machine stability. Further, it was shown that a recovery motion by the manipulator could prevent some tip-over occurrences.

Dynamic instabilities of a MEWP due to wind excitation have been analyzed (Bošnjak et al., 2009). Using a single-DOF model of a boom-type lift, it was determined wind velocities within the operating range of a MEWP may cause resonance. At the resonance state, wind-induced vibrations could produce stresses resulting in structural failure. 
Further, galloping vibrations of the MEWP, which are high amplitude at low-frequencies, may develop under the permissible range of wind velocities. The results indicate that using multiplier factors in static calculations, as suggested in ISO 16368, are not sufficient in analyzing the stability of a MEWP under wind loading.

\subsection{Overview of ADAMS}

ADAMS $^{\circledR}$ (Automatic Dynamic Analysis of Mechanical Systems) is a multibody dynamics software, which allows users to create, simulate, and optimize complex mechanical systems. ADAMS performs the following tasks for a simulation: (1) initial conditions for all bodies in the system are set, (2) using the laws of Newtonian mechanics, ADAMS formulates the proper equations of motion which predict how the bodies of the system will react to the forces and constraints applied on them, (3) solves the equations of motion to a specified tolerance, (4) saves the data generated from the simulation for analysis of the results (MSC Software Corporation). The following types of simulations can be performed using ADAMS: static, kinematic, dynamic, initial conditions, and linear.

A static simulation solves for displacements and static forces, but neglects velocity, acceleration, and inertia forces. In kinematic analysis, ADAMS uses Newton-Raphson iteration to solve the nonlinear algebraic constraint equations for the displacements, velocities, accelerations, and forces. This process is repeated for each step in the simulation to find the current values. A kinematic analysis is only recommended for zero degree of freedom systems and it is independent of the applied forces. Dynamic simulations consider the effects of forces and constraints to determine the motion of 
bodies over a specified time. Using various numerical algorithms, ADAMS provides an approximate solution to the equations of motion. For an initial conditions simulation, the constraints of the system are verified. ADAMS has the ability to move parts so that contact is made between the parts being constrained. Last, a linear simulation calculates the eigenvalues and eigenvectors at a specified operating point for a linear representation of the model.

\subsection{Applications of ADAMS}

The various types of simulation performed using ADAMS allow users to conduct virtual tests in significantly less time than a physical test. Parametric studies leading to design optimization can be achieved without having to physically build prototypes. Also, hazardous test scenarios could be too dangerous to perform in reality, but can be examined through virtual simulation. As a result, ADAMS has been used to analyze a variety of mechanical systems.

Vehicle rollover criteria have been studied using a simplified rigid body model (Kim et al., 2006). Tripped and untripped rollover simulations were performed on this unsuspended model using ADAMS. The critical rollover velocity obtained from the tripped rollover simulation was nearly the same as the theoretical value from the Initial Kinetic Energy (IKE) criterion (Kim et al., 2006).

Motorcycle handling maneuvers have been analyzed with a multibody simulation model in ADAMS/motorcycle (Capitani et al., 2006). The geometry, inertial characteristics, and dynamic parameters of the model were derived from an actual motorcycle. Validation of the motorcycle model was achieved by comparing simulation 
responses with experimental responses for various handling maneuvers. The signals for roll angle, steering angle, and steering torque were similar for the simulation and actual maneuvers. It was concluded a multibody motorcycle model could effectively be used to study handling maneuvers.

Using parameters from an actual tractor (geometry, inertia, tire, etc.), a multibody dynamic model of a typical farm tractor has been analyzed using ADAMS/Car ${ }^{\circledR}$ (Previati et al., 2007). The model was dynamically validated by comparison of its responses to experimental results for various maneuvers. Measurements were recorded for experimental on-road, off-road, and indoor tests and the simulation responses to these tests were very similar. The study suggests a multibody model of a farm tractor could accurately simulate various dynamic conditions.

The previously mentioned studies indicate that multibody dynamics software, such as $\mathrm{ADAMS}^{\circledR}$, can be a powerful tool in the analysis of mechanical systems. The general approach used in these simulation models' development consists: (1) constructing the rigid bodies based on the geometry and inertia properties of the actual components of the analyzed system (2) assembling the rigid bodies with appropriate constraints or joints (3) and validation of the model using experimental or analytical data. Once the model has been validated, parametric studies and optimization can be performed on the mechanical system. 


\section{Chapter 3: Method}

\subsection{Examined Scissor Lift}

The scissor lift used for this study was a typical compact scissor lift, as shown in Fig.

1. The examined lift is a compact DC electric powered lift, which features a variable speed, front wheel hydraulic drive. It has a width of $0.81 \mathrm{~m} \mathrm{(32} \mathrm{in.)} \mathrm{and} \mathrm{a} \mathrm{length} \mathrm{of} 1.78$ $\mathrm{m}$ (70 in.). The lift is equipped with a $0.9 \mathrm{~m}$ platform extension and can support two workers. It has a vehicle weight of $1170 \mathrm{~kg}(2579 \mathrm{lbs})$ and a total load capacity of $250 \mathrm{~kg}$ (550 lbs). The main platform of the lift is rated for $137 \mathrm{~kg}(300 \mathrm{lbs})$ and the platform

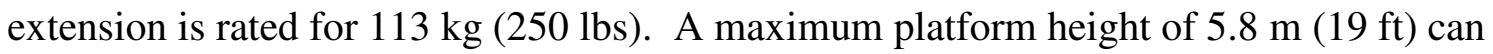
be achieved with this lift. At the stowed height $(0.99 \mathrm{~m})$, the lift has a maximum speed of $0.89 \mathrm{~m} / \mathrm{s}(2 \mathrm{mph})$. In addition, the lift can travel $0.29 \mathrm{~m} / \mathrm{s}(0.7 \mathrm{mph})$ at elevated heights greater than $7 \mathrm{ft}$.

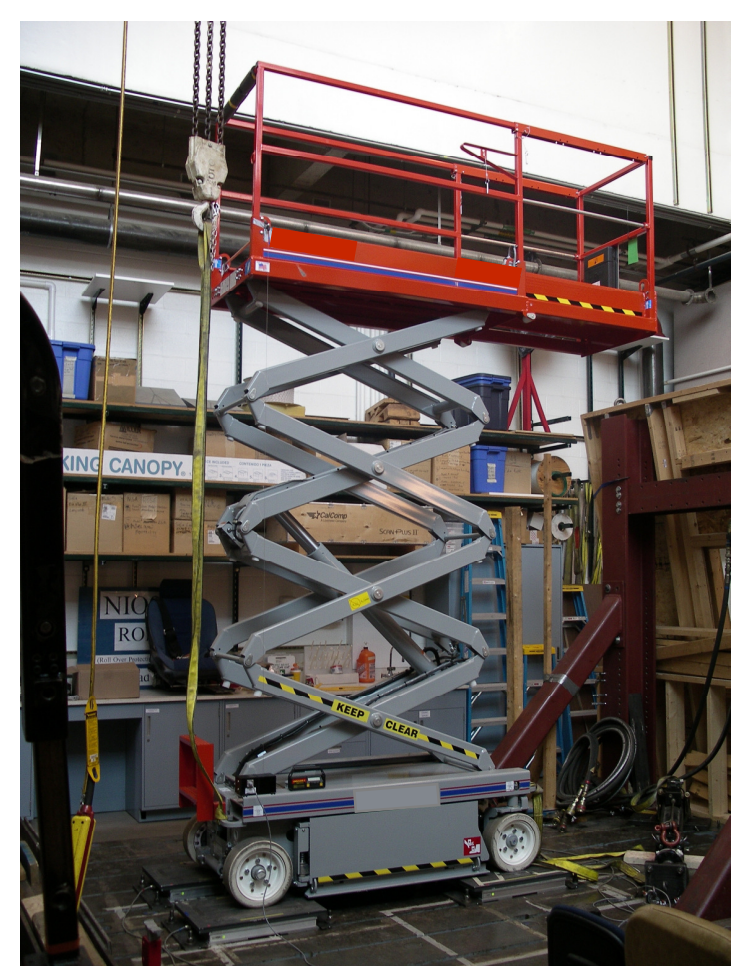

Fig. 1: Examined scissor lift 
This particular scissor lift has several safety features to protect the workers. In order to confine the workers to the platform, a guardrail system surrounds the working platform. The top guardrail has a height from 39 " to 43.5 ". In addition, mid-rails and toe boards surround the working platform. If the lift is elevated (above $\sim 6 \mathrm{ft}$ ), a tilt sensing device restricts the vehicle from driving or lifting when the lift is exposed to a lateral slope of $1.5^{\circ}$ or a longitudinal slope of $3.5^{\circ}$. However, lowering of the lift can be performed during this time. The operator is notified about this condition by an audible alarm. To provide stability to the lift during a drop-off or pothole contact, the lift is equipped with a pothole protection device. The pothole protection device consists of a mechanically actuated steel assembly that reduces ground clearance. Driving is disabled if the pothole protection device is not fully lowered. Last, an emergency lowering system is located at the base of the lift. The emergency lowering system allows the platform to be lowered in case of an emergency or electrical failure.

\subsection{Experiments}

In order to validate the dynamic model of the scissor lift, measurements were used from previously conducted experiments. The simulated scissor lift's geometric, mass, and dynamic properties were based on the actual scissor lift examined in these experimental tests. The center of gravity $(\mathrm{CG})$ of the scissor lift was experimentally determined for five different platform heights: stowed position, $1 \mathrm{~m}, 1.52 \mathrm{~m}, 2.14 \mathrm{~m}$, and $3.05 \mathrm{~m}$ (Ronaghi et al., 2009). These platform heights were measured using a cableextension transducer (Model PT5A-250-N34-UP-500-C25, Celecsco). The CG in the longitudinal (X-axis) and lateral (Z-axis) directions was calculated using force plates 
(Bertec) under each wheel of the lift. For the calculation of vertical component (Y-axis) of the CG, hand pump jacks and jack stands were used to tilt the scissor lift around lateral axis. The results of this experiment are shown in section 4.1 .

Dynamic curb impact and depression tests, described in an ISO standard (ISO 16368, 2003) were performed by NIOSH collaborators. The test setup is shown below in Fig. 2 . The scissor lift traveled on a level surface in both tests. In the dynamic curb impact test, the lift was elevated to full height $(5.8 \mathrm{~m})$ then directly impacted a curb at its maximum elevated driving speed $(0.29 \mathrm{~m} / \mathrm{s})$. For the depression test, the scissor lift was fully elevated then driven at it normal elevated speed until a front wheel dropped into a standardized pothole. Using two tri-axial accelerometers (Kionix, Model KXM52-1050), the acceleration responses for these tests were measured at the base and main platform of lift. The measured responses from these tests are further discussed in section 4.1.

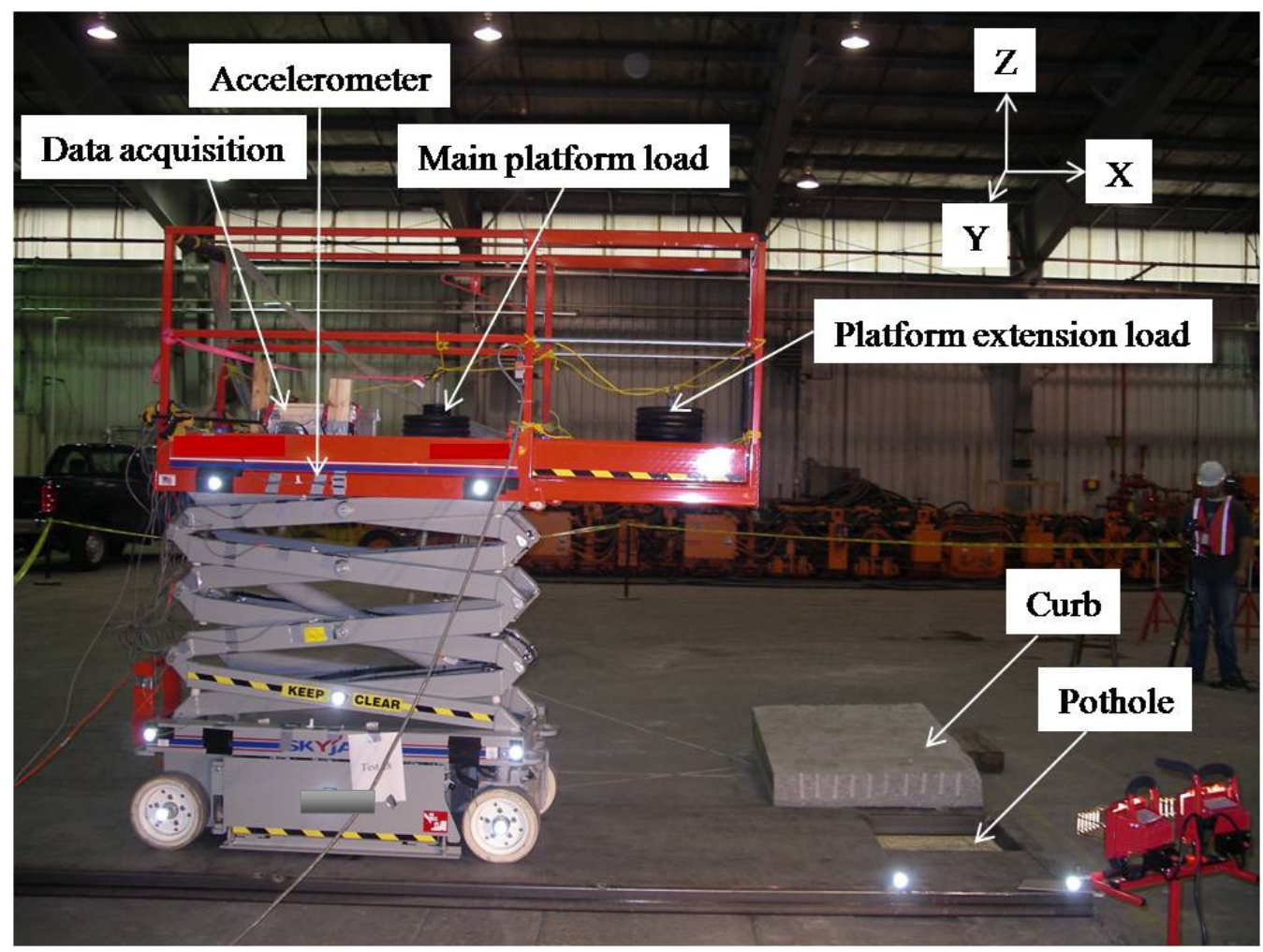

Fig. 2: A pictorial view of the tested scissor lift and the experimental site 
Last, a manikin drop test, shown in Fig. 3, was performed by NIOSH collaborators. In this experiment, an Advanced Dynamic Anthropomorphic Manikin (1998 ADAM $^{\mathrm{TM}}$, Veridian, Dayton, $\mathrm{OH}$ ) was dropped from a scissor lift, while the lift was fully extended $(5.8 \mathrm{~m})$. Energy absorbing lanyards (EALs) were connected from the top-rail of the lift to the safety harness worn by the manikin. This represents a misuse condition since the fall protection system should be connected to anchorage points on the work platform not the guardrail. Initially, the manikin was positioned to the desired drop location by a 5-ton crane. During each drop test, the fall arrest force of the lanyard was measured using a load cell (3000 lb (13.4 kN), S-type, Interface Inc, Scottsdale, Arizona, USA). Additionally, the manikin accelerations at the head, middle of spine, and torso were measured via built-in uni-axial accelerometers (Entran EAX series). Measurements were recorded for two drop heights: $1.83 \mathrm{~m}(6 \mathrm{ft})$ and $3.35 \mathrm{~m}(11 \mathrm{ft})$.

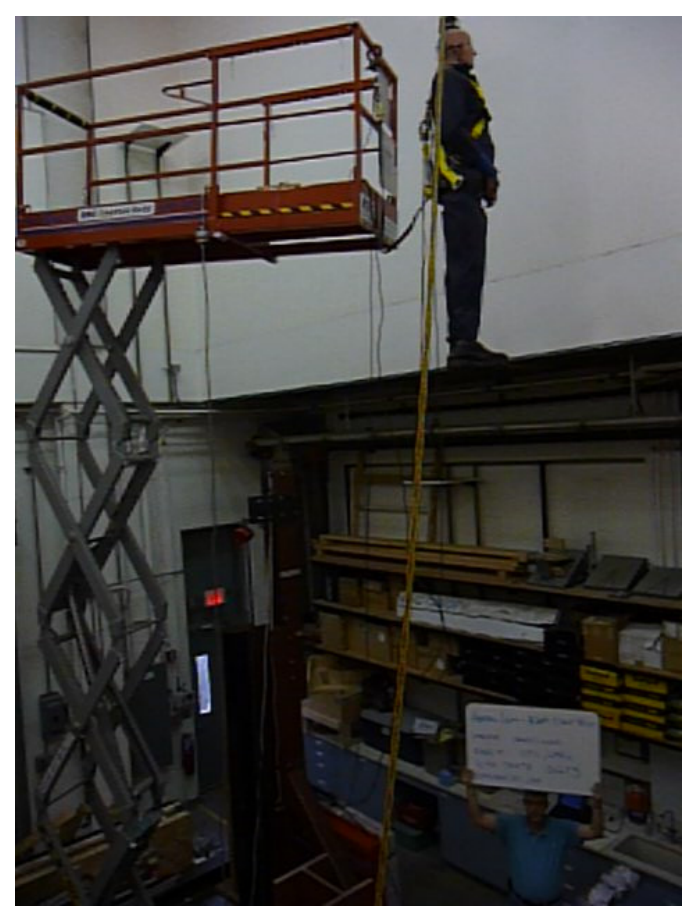

Fig 3: Experimental manikin drop test 


\subsection{Modeling Overview}

The multibody model of the scissor lift with identified parts, constraints, and other connections is shown in Fig. 4 and 5. The parameters of these elements are described in detail in Section 3.4, 3.5, and 3.6. The ID numbers shown in Fig. 4 and 5 are referenced in these sections. The actual scissor lift does not have suspension between the base and wheels. Therefore, the wheels in the scissor lift model are rigidly connected to the base. In reality, the wheels are controlled hydraulically to allow turning but this motion was not of concern for the study. The low speeds $(0.89 \mathrm{~m} / \mathrm{s} \max )$ of the examined scissor lift are not likely to generate centrifugal forces that would significantly affect the lift's stability. Each wheel is constrained to the road using a solid-to-solid contact force. The road was modeled as a rigid body with a smooth surface. A solid-to-solid contact was made between the front wheels and the curb for the curb impact simulation. As mentioned earlier, the scissor lift is equipped with a pothole protection device. A solid-to-solid contact was made between the pothole protection device and the leading edge of the pothole in road.

The lifting mechanism of the scissor lift consists of a scissor-type assembly and hydraulic actuator system. Four inner and outer frame members are connected by revolute joints to form the scissor-type assembly. In order to account for the flexibility of the scissor lift, four connections were made between the scissor assembly and the base of the lift. The inner scissor frame 1 was connected to the rear of the base with two identical linear bushing elements. Also, the outer scissor frame member 1 was connected to the front of the base with two identical solid-to-solid contacts. These contacts allow the outer frame member to slide along the base in the longitudinal direction (X-axis), thus 


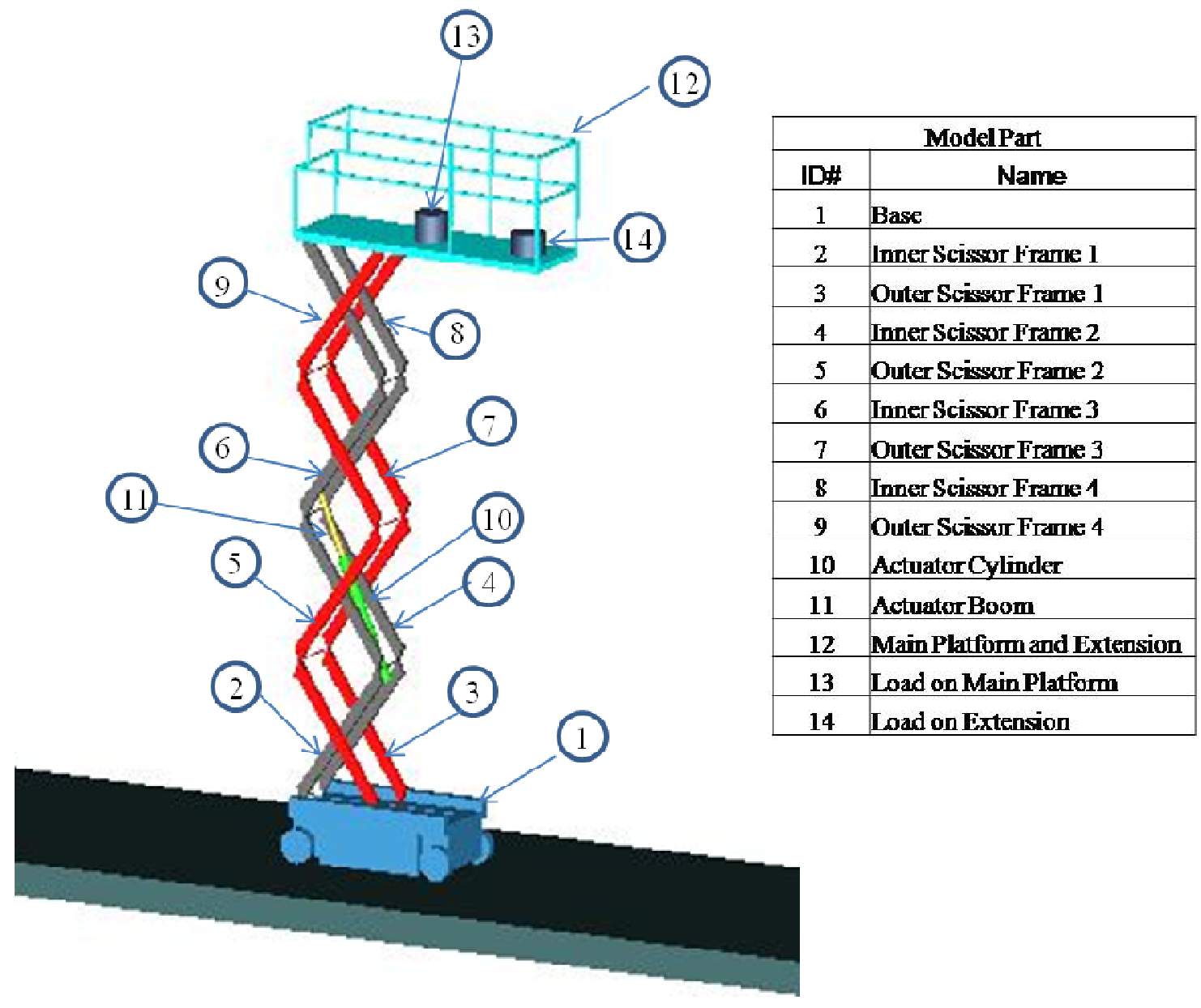

Fig. 4: Scissor lift model with identified parts 


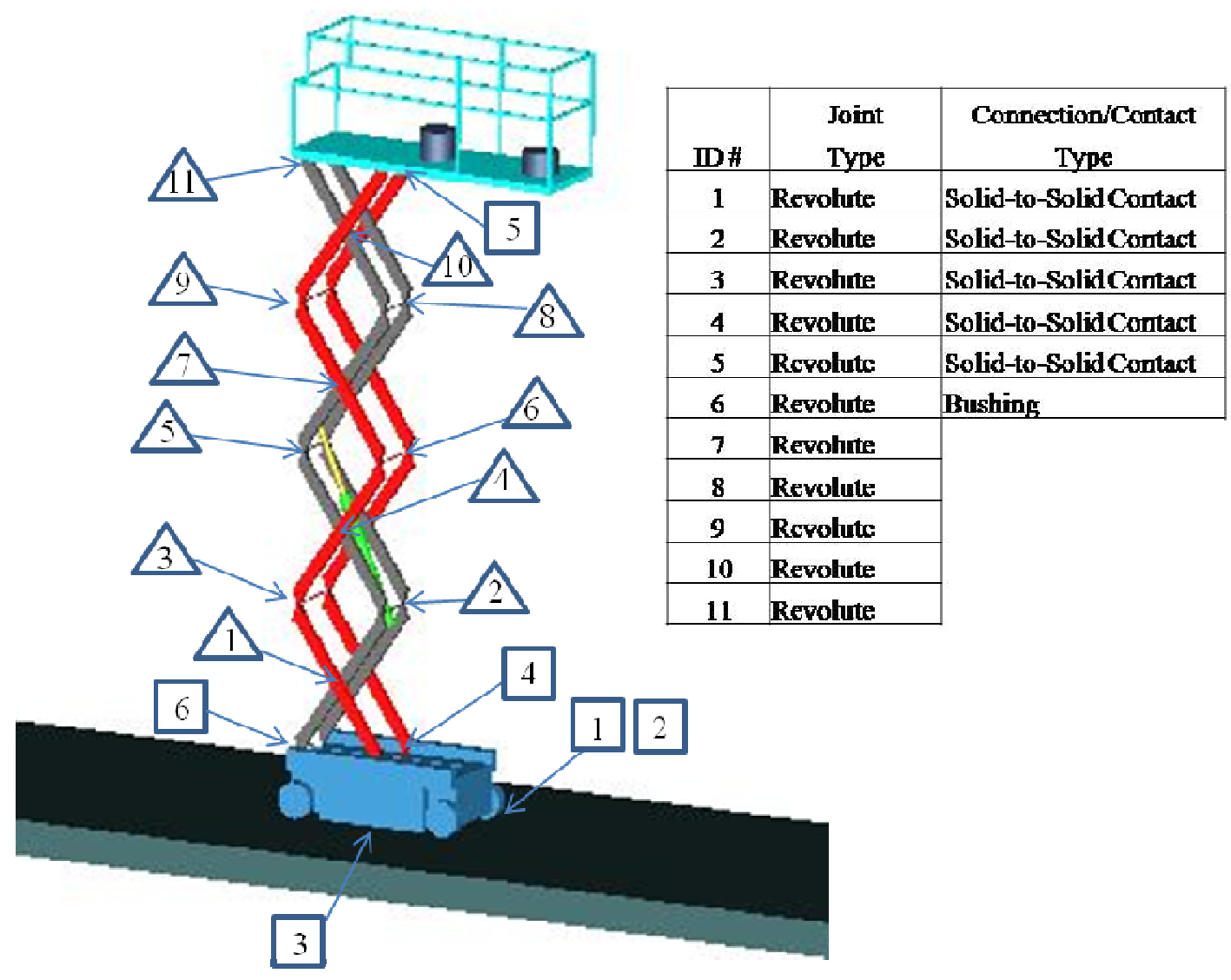

Fig. 5: Scissor lift model with identified constraints $(\Delta)$, and connections/contacts ( $\square$ ) 
allowing the raising and lowering of the scissor assembly. In order to prevent the outer scissor frame member 1 from lifting off the base, an additional solid-to-solid contact was placed between it and the base. This contact allows a small vertical movement $(2.0 \mathrm{~mm})$ of the outer frame member, which is consistent with the actual scissor-type assembly.

The scissor-type assembly is connected to the working platform with a revolute joint between the inner scissor frame 4 and the rear of the platform. In addition, two identical solid-to-solid contacts were made between rollers, which were rigidly connected to outer scissor frame 4, and the bottom of the platform. These contacts let the rollers of the outer scissor frame 4 to travel longitudinally along the bottom of the platform which allows the scissor-type assembly raise and lower. A platform extension, rigidly connected to the main platform, was fully extended for the simulations. The rated loading for this particular lift were modeled as fixed loads on the platform and extension. Their placements and magnitudes were consistent with the loads applied during experimental testing.

The actuator assembly of the scissor lift was modeled with three rigid bodies, as shown in Fig. 6. The cylinder was connected to inner scissor frame 1 by a revolute joint. A revolute joint was also used to connect the boom to inner scissor frame 3 . The boom was constrained to the cylinder by a translational joint. A pseudo piston, which has a negligible mass, was created to provide motion and flexibility to the actuator. A cylindrical joint constrains the pseudo piston to the cylinder. Elevation of lift was achieved by applying translational motion to this joint in the form of a ramp function, which is shown in Fig. 7. Under certain dynamic conditions, the main platform 


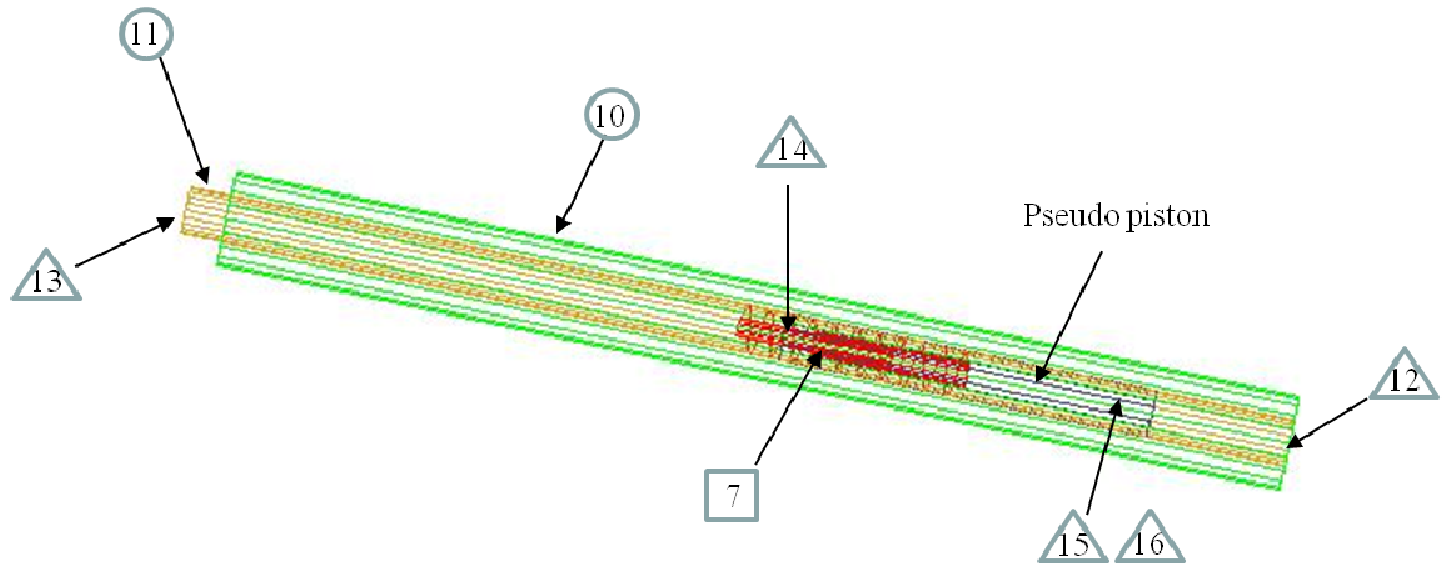

\begin{tabular}{|c|l|l|l|}
\hline ID\# & \multicolumn{1}{|c|}{$\begin{array}{c}\text { Part } \\
\text { Name }\end{array}$} & $\begin{array}{c}\text { Joint } \\
\text { Type }\end{array}$ & $\begin{array}{c}\text { Connection/Contact } \\
\text { Type }\end{array}$ \\
\hline 7 & & & \multirow{2}{*}{ Spring-Damper } \\
\hline 10 & ActuatorCylinder & & \multirow{2}{*}{} \\
\hline 11 & ActuatorBoom & & \\
\hline 12 & & Revolute & \\
\hline 13 & & Revolute & \\
\hline 14 & & Translational \\
\hline 15 & & Cylindrical & \\
\hline 16 & & Motion \\
\hline
\end{tabular}

Fig. 6: Actuator assembly with identified parts (०), joints $(\Delta)$, and connections $(\square)$

experiences a bouncing motion that can partially be attributed to the flexibility of the actuator. The pseudo piston was connected to the boom with a spring-damper element to account for this flexibility.

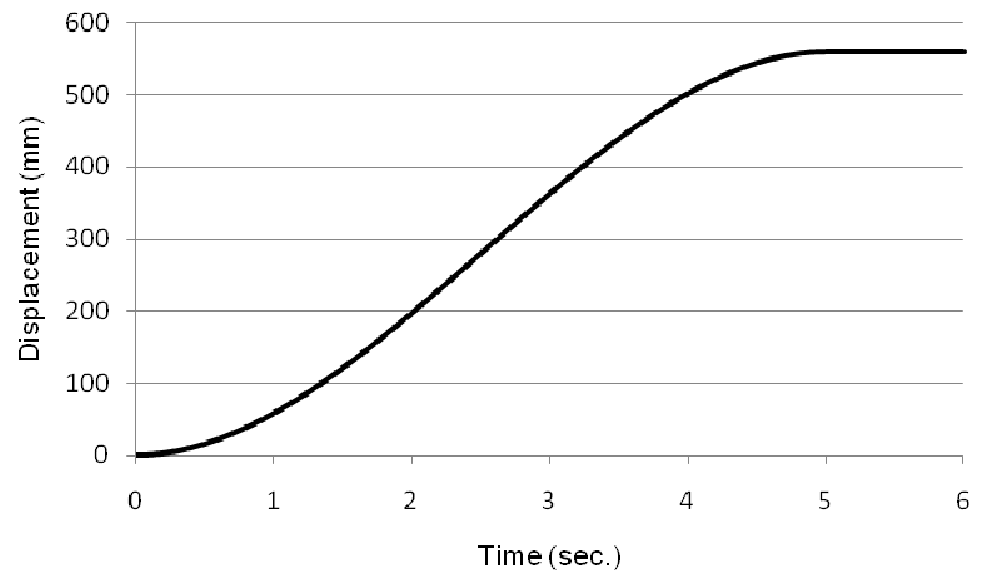

Fig. 7: Piston motion as described by a ramp function 


\subsection{Rigid Body Construction}

The multibody model of the examined scissor lift, shown in Fig. 4, was constructed using an advanced modeling platform - ADAMS ${ }^{\circledR}$. ADAMS is a dynamics modeling platform that allows the user to construct mechanical systems then perform dynamic analysis of the system. Components of the system can be created using the geometric modeling tool stack. In addition, component geometry can be imported from other CAD programs in a variety of formats. For this model, the components were created based on technical drawings from the manufacturer. Geometry, major mass properties, and constraint locations of the components were developed from the corresponding parts/assemblies of the actual lift.

In actuality, the scissor lift consists of several components. For instance, the base of the lift contains many mechanical components, batteries, and electrical devices. Modeling every component of the scissor lift would be impractical. In order to simplify the model construction, lumped mass parameters were used. For instance, every component located within the base was merged to form one solid body. As a result, the scissor lift model consists of 12 components. Additionally, fixed loads on the platform $(137 \mathrm{~kg})$ and extension $(113 \mathrm{~kg})$ were modeled in the same locations as those in the experiments. The motion associated with the deformation of these bodies was assumed to be small in comparison to the overall motion of the system. Therefore, all components of the scissor lift model were created as rigid bodies. The total mass of the scissor lift model with platform loading is $1419.21 \mathrm{~kg}$, which is nearly the same as the actual scissor lift with maximum platform loading $(1420 \mathrm{~kg})$. The center of mass and major mass properties of the components are shown in Table 1. The origin of the global coordinate 
system is on the road surface and the center of mass properties of the components are at the lift's initial position.

Table 1: Global coordinates of the center of mass (CM) of the lumped parts in the scissor lift model at stowed position (without static equilibrium) and their mass properties ( $m$ - mass; $I x$ - moment of inertia around $X$-axis; $I y$ - moment of inertia around $Y$-axis; $I z$ - moment of inertia around $Z$-axis).

\begin{tabular}{|c|c|c|c|c|c|c|c|c|}
\hline \multicolumn{2}{|c|}{ Model Part } & \multicolumn{3}{|c|}{$\begin{array}{l}\text { CM in Global Coordinate } \\
\text { System }(\mathrm{mm})\end{array}$} & \multicolumn{4}{|c|}{$\begin{array}{c}\text { Major Mass Properties Referred to CM local } \\
\text { coordinate system }\end{array}$} \\
\hline ID\# & Name & $X$ & $Y$ & $Z$ & $\begin{array}{c}M \\
(\mathrm{~kg})\end{array}$ & $\begin{array}{c}I x \\
\left(\mathrm{~kg} \cdot \mathrm{mm}^{\wedge} 2\right)\end{array}$ & $\begin{array}{c}I y \\
\left(\mathrm{~kg} \cdot \mathrm{mm}^{\wedge} 2\right)\end{array}$ & $\begin{array}{c}I z \\
\left(\mathrm{~kg} \cdot \mathrm{mm}^{\wedge} 2\right)\end{array}$ \\
\hline 1 & Base & 3.00 & 0.00 & 225.00 & 651.39 & 55408558 & 146759154 & 177623590 \\
\hline 2 & $\begin{array}{l}\text { Inner Scissor } \\
\text { Frame } 1\end{array}$ & 92.00 & 0.00 & 562.61 & 42.50 & 956484 & 6065728 & 6889100 \\
\hline 3 & $\begin{array}{l}\text { Outer Scissor } \\
\text { Frame } 1\end{array}$ & 0.00 & 0.00 & 565.05 & 41.65 & 2767716 & 10829473 & 13504918 \\
\hline 4 & $\begin{array}{l}\text { Inner Scissor } \\
\text { Frame } 2\end{array}$ & 0.00 & 0.00 & 679.35 & 38.06 & 1168597 & 7735394 & 8815705 \\
\hline 5 & $\begin{array}{l}\text { Outer Scissor } \\
\text { Frame } 2\end{array}$ & 0.00 & 0.00 & 679.35 & 40.73 & 2583496 & 10238627 & 12683967 \\
\hline 6 & $\begin{array}{l}\text { Inner Scissor } \\
\text { Frame } 3\end{array}$ & -88.00 & 0.00 & 796.09 & 50.50 & 1279064 & 9291528 & 10437480 \\
\hline 7 & $\begin{array}{l}\text { Outer Scissor } \\
\text { Frame } 3\end{array}$ & 0.00 & 0.00 & 793.65 & 40.73 & 2445136 & 7603673 & 9956538 \\
\hline 8 & $\begin{array}{l}\text { Inner Scissor } \\
\text { Frame } 4 \\
\end{array}$ & 0.00 & 0.00 & 907.95 & 38.06 & 1168597 & 7735394 & 8815705 \\
\hline 9 & $\begin{array}{l}\text { Outer Scissor } \\
\text { Frame } 4\end{array}$ & 0.00 & 0.00 & 907.95 & 43.24 & 2583496 & 10238627 & 12683967 \\
\hline 10 & $\begin{array}{l}\text { *Actuator } \\
\text { Cylinder }\end{array}$ & 62.02 & 0.00 & 664.35 & 22.00 & 1906891 & 33751 & 1906891 \\
\hline 11 & $\begin{array}{l}* \text { Actuator } \\
\text { Boom }\end{array}$ & 13.11 & 0.00 & 674.75 & 15.00 & 1236830 & 13997 & 1236830 \\
\hline 12 & $\begin{array}{l}\text { Main Platform } \\
\text { and Extension }\end{array}$ & 344.00 & 0.00 & 1020.00 & 146.15 & 25717971 & 96866038 & 95087721 \\
\hline 13 & $\begin{array}{l}\text { Load on Main } \\
\text { Platform }\end{array}$ & 600.00 & 0.00 & 1125.00 & 136.00 & 1473333 & 1473333 & 1530000 \\
\hline 14 & $\begin{array}{l}\text { Load on } \\
\text { Extension }\end{array}$ & 1400.00 & 0.00 & 1100.00 & 113.00 & 1012292 & 1012292 & 1271250 \\
\hline
\end{tabular}

* The orientation of each CM local coordinate system is the same as that of the global coordinate system except those of the actuator cylinder and boom. Different from the other parts, the orientation of the Y-axis for the actuator cylinder and boom in this table is along the longitudinal axis of the actuator. 


\subsection{Kinematic Constraints}

The rigid bodies of the scissor lift were assembled using various kinematic constraints or joints. In reality, joints within mechanical systems are not ideal, meaning that clearances, deformations, and effects from lubrication are likely (Flores et al., 2008). While these variables can affect a system's dynamic behavior, the modeling of imperfect joints is a difficult task. Determining joint clearances, coefficients of friction, and other parameters of the actual joints would be impractical. As a result, the kinematic joints used in the modeling were idealistic joints. Table 2 lists the idealistic kinematic joints of the scissor lift model.

Table 2: Kinematic joints of the scissor lift model

\begin{tabular}{lllll} 
ID & $\begin{array}{c}\text { Joint } \\
\text { Type }\end{array}$ & \multicolumn{1}{c}{ Part I } & \multicolumn{1}{c}{ Part J } & $\begin{array}{c}\text { No. of } \\
\text { Constraints }\end{array}$ \\
\hline 1 & Revolute & Outer Scissor Frame 1 & Inner Scissor Frame 1 & 5 \\
\hline 2 & Revolute & Inner Scissor Frame 2 & Inner Scissor Frame 1 & 5 \\
\hline 3 & Revolute & Outer Scissor Frame 2 & Outer Scissor Frame 1 & 5 \\
\hline 4 & Revolute & Outer Scissor Frame 2 & Inner Scissor Frame 2 & 5 \\
\hline 5 & Revolute & Inner Scissor Frame 3 & Inner Scissor Frame 2 & 5 \\
\hline 6 & Revolute & Outer Scissor Frame 3 & Outer Scissor Frame 2 & 5 \\
\hline 7 & Revolute & Outer Scissor Frame 3 & Inner Scissor Frame 3 & 5 \\
\hline 8 & Revolute & Inner Scissor Frame 4 & Inner Scissor Frame 3 & 5 \\
\hline 9 & Revolute & Outer Scissor Frame 4 & Outer Scissor Frame 3 & 5 \\
\hline 10 & Revolute & Outer Scissor Frame 4 & Inner Scissor Frame 4 & 5 \\
\hline 11 & Revolute & Main Platform & Inner Scissor Frame 4 & 5 \\
\hline 12 & Revolute & Actuator Cylinder & Inner Scissor Frame 1 & 5 \\
\hline 13 & Revolute & Actuator Boom & Inner Scissor Frame 3 & 5 \\
\hline 14 & Translational & Actuator Cylinder & Actuator Boom & 5 \\
\hline 15 & Cylindrical & Pseudo Piston & Actuator Cylinder & 4 \\
\hline 16 & Motion & & Joint 15 & 1 \\
\hline
\end{tabular}


These kinematic joints impose restrictions on the relative motion of bodies within the system. In three-dimensional space, the vector of coordinates for a body $i$ can be expressed as:

$$
q_{i}=\left[x, y, z, \emptyset_{1}, \emptyset_{2}, \emptyset_{3}\right]_{i}^{T}
$$

The algebraic kinematic constraint equation describing a stipulation on vector of coordinates can be defined by the following:

$$
\Phi(\boldsymbol{q}, t)=0
$$

From the algebraic equations shown in Table 3, commonly used kinematic joints can be described. Each kinematic constraint equation removes one degree of freedom (DoF) from the system. For instance, a revolute joint between the inner scissor frame 1 and inner scissor frame 2 consists of all three translational constraint equations and two rotational constraint equations, thereby removing five DoF. The cylindrical joint between the actuator and the pseudo piston consists of two translational constraint equations and two rotational constraint equations, which combined remove $4 \mathrm{DoF}$ in the system.

In order to determine the total DoF in the scissor lift model, Gruebler's equation can be applied to the system:

$$
D o F=6(n-1)-5 f_{1}-4 f_{2}-3 f_{3}-2 f_{4}-1 f_{5}
$$

where:

- $\mathrm{n}$ is the number of rigid bodies, including ground, in the system

- $\mathrm{f}_{1}$ is the number of joints allowing one DoF

- $\mathrm{f} 2$ is the number of joints allowing two DoF

- $\mathrm{f3}$ is the number of joints allowing three DoF

- $\mathrm{f} 4$ is the number of joints allowing four DoF

- $\mathrm{f5}$ is the number of joints allowing five DoF 
Table 3: Algebraic kinematic constraint equations (MSC Software Corp.)

\begin{tabular}{|c|c|}
\hline The equation: & Means That: \\
\hline$x_{i}-x_{j}=0$ & $\begin{array}{l}\text { Global } \mathrm{x} \text { coordinate of the I marker must always remain identical to } \\
\text { the global } \mathrm{x} \text { coordinate of the } \mathrm{J} \text { marker. }\end{array}$ \\
\hline$y_{i}-y_{j}=0$ & $\begin{array}{l}\text { Global y coordinate of the I marker must always remain identical to } \\
\text { the global } x \text { coordinate of the } J \text { marker. }\end{array}$ \\
\hline$z_{i}-z_{j}=0$ & $\begin{array}{l}\text { Global } \mathrm{z} \text { coordinate of the I marker must always remain identical to } \\
\text { the global } \mathrm{z} \text { coordinate of the } \mathrm{J} \text { marker. }\end{array}$ \\
\hline$\hat{z}_{i} \cdot \hat{x}_{j}=0$ & $\begin{array}{l}\mathrm{Z} \text {-axis of the I marker must always remain perpendicular to the } \mathrm{x}- \\
\text { axis of the } \mathrm{J} \text { marker (which means no rotation about the common } \mathrm{y} \text { - } \\
\text { axis). }\end{array}$ \\
\hline$\hat{z}_{i} \cdot \hat{y}_{j}=0$ & $\begin{array}{l}\mathrm{Z} \text {-axis of the I marker must always remain perpendicular to the } \mathrm{y}- \\
\text { axis of the } \mathrm{J} \text { marker (which means no rotation about the common } \mathrm{x}- \\
\text { axis). }\end{array}$ \\
\hline$\hat{x}_{i} \cdot \hat{y}_{j}=0$ & $\begin{array}{l}\mathrm{X} \text {-axis of the I marker must always remain perpendicular to the } \mathrm{y}- \\
\text { axis of the } \mathrm{J} \text { marker (which means no rotation about the common } \mathrm{z}- \\
\text { axis). }\end{array}$ \\
\hline
\end{tabular}

Including the ground, the scissor lift model has 17 bodies. However, some of these bodies are rigidly fixed to other bodies thereby removing all six DoF. Such is the case with the fixed loads, platform extension, and the road surface. Also, the translational motion applied to the cylindrical joint, which provides the lifting motion, removes one DoF. Using equation (5) for the scissor lift model, results in three DoF system. A model verification using ADAMS also results in three DoF, but the ADAMS verification identifies 12 redundant constraint equations. These redundant constraint equations are related to revolute joints of the scissor structure. Some of the revolute joints remove the same DoF within the system. In actuality, the scissor structure's frame proportions and joint clearances allow for the proper elevating motion. Theoretically, some these joints could be replaced with spherical joints to remove the redundant constraints while still providing the desired motion. However, ADAMS ignores these redundant constraints and determines the physically accurate motion. 
By removing the 12 redundant constraint equations, the scissor lift model has 15 DoF. Since contact forces were used between the base and road, the base has all 6 DoF. Similarly, the bushings and contact forces between the scissor structure and the base do not remove any DoF. Therefore, the entire scissor structure has 6 DoF relative to the base. The revolute joint between the scissor structure and the platform allows 1 DoF, which is platform rotation around the Y-axis. With the use of the pseudo piston, the actuator boom is able to translate within the cylinder, thereby providing $1 \mathrm{DoF}$. Last, the pseudo piston can rotate with the cylinder which provides another DoF. Table 4 summarizes the DoF within the model.

Table 4: Allowable degrees of freedom for model

\begin{tabular}{|l|l|c|c|c|c|c|c|c|}
\cline { 3 - 9 } \multicolumn{2}{c|}{} & \multicolumn{3}{c|}{ Translation } & \multicolumn{4}{c|}{ Rotation } \\
\hline \multicolumn{2}{c|}{ Bodies } & \multicolumn{1}{c|}{$\mathrm{x}$} & $\mathrm{y}$ & $\mathrm{Z}$ & $\mathrm{x}$ & $\mathrm{y}$ & $\mathrm{z}$ \\
\hline Base & Road & $\mathrm{X}$ & $\mathrm{X}$ & $\mathrm{X}$ & $\mathrm{X}$ & $\mathrm{X}$ & $\mathrm{X}$ \\
\hline Scissor Structure & Base & $\mathrm{X}$ & $\mathrm{X}$ & $\mathrm{X}$ & $\mathrm{X}$ & $\mathrm{X}$ & $\mathrm{X}$ \\
\hline Platform & Scissor Structure & & & & & $\mathrm{X}$ & \\
\hline Boom & Cylinder & & $\mathrm{X}$ & & & & \\
\hline Pseudo Piston & Cylinder & & & & & $\mathrm{X}$ & \\
\hline
\end{tabular}

\subsection{Contacts and Connections}

As previously mentioned solid-to-solid contacts were used at various locations in the scissor lift model. The IMPACT function model was used to calculate the normal force for the solid-to-solid contacts in ADAMS ${ }^{\circledR}$. In Fig. 8, two bodies are shown with and 


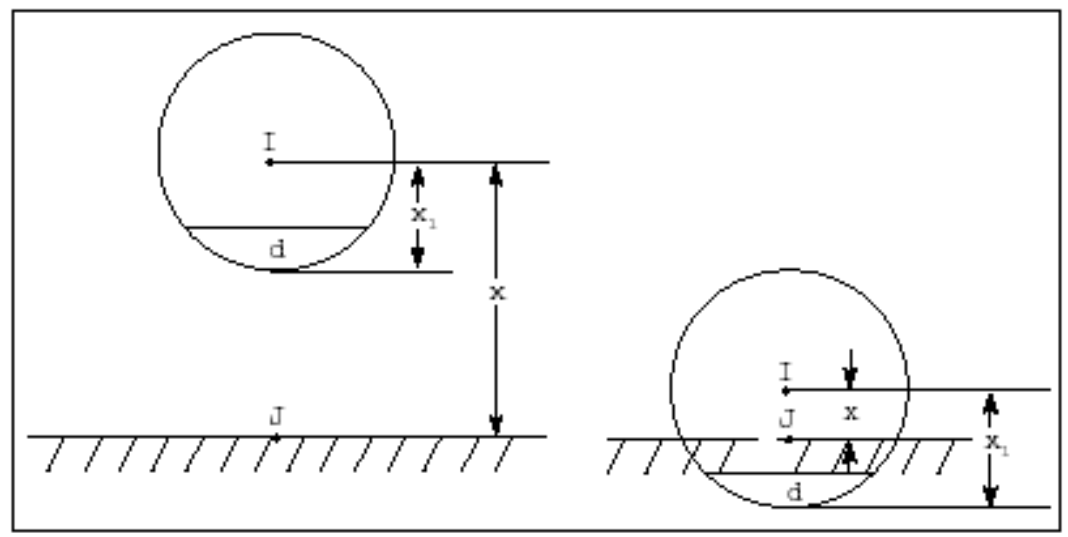

Fig. 8: Illustration of impact (MSC Software Corporation)

without contact. The IMPACT function treats the contact force as a nonlinear springdamper as is defined by the following:

$F_{n}=\operatorname{Max}\left(0, k\left(x_{1}-x\right)^{e}-\operatorname{Step}\left(x, x_{1}-d, c_{\max }, x_{1}, 0\right) \cdot \dot{x}\right) \quad(12)$ when $\mathrm{x}<\mathrm{x}_{1}$ and

$F_{n}=0$ when $\mathrm{x} \geq \mathrm{x}_{1}$,

where:

- $\quad F_{n}$ is the normal force

- $\quad k$ is stiffness of the material

- $\quad e$ is the exponent of the force exponent characteristic

- $d$ is the boundary penetration at which full damping is applied

- $\quad c_{\text {max }}$ is the maximum damping coefficient

- $x$ is the distance from the center of mass of one body to the surface of the other body

- $x_{1}$ is free length of $x$

If contact is made between two bodies, the normal force is calculated by Eq. (12). When a contact does not exist the normal force is zero, as shown is Eq. (13). In addition to the normal force, a Coulomb friction force exists during contact. A velocity-based friction model is used by ADAMS for determining frictional forces at contact.

A linear bushing element, which is a type of flexible connection, was used to connect the inner scissor frame 1 to the base. The following constitutive equations are used in ADAMS to define the bushing element: 


$$
\left[\begin{array}{c}
F_{x} \\
F_{y} \\
F_{z} \\
T_{x} \\
T_{y} \\
T_{z}
\end{array}\right]=-\left[\begin{array}{cccccc}
K_{11} & 0 & 0 & 0 & 0 & 0 \\
0 & K_{22} & 0 & 0 & 0 & 0 \\
0 & 0 & K_{33} & 0 & 0 & 0 \\
0 & 0 & 0 & K_{44} & 0 & 0 \\
0 & 0 & 0 & 0 & K_{55} & 0 \\
0 & 0 & 0 & 0 & 0 & K_{66}
\end{array}\right]\left[\begin{array}{c}
x \\
y \\
z \\
a \\
b \\
c
\end{array}\right]-\left[\begin{array}{cccccc}
C_{11} & 0 & 0 & 0 & 0 & 0 \\
0 & C_{22} & 0 & 0 & 0 & 0 \\
0 & 0 & C_{33} & 0 & 0 & 0 \\
0 & 0 & 0 & C_{44} & 0 & 0 \\
0 & 0 & 0 & 0 & C_{55} & 0 \\
0 & 0 & 0 & 0 & 0 & C_{66}
\end{array}\right]\left[\begin{array}{c}
V_{x} \\
V_{y} \\
V_{z} \\
\omega_{x} \\
\omega_{y} \\
\omega_{z}
\end{array}\right]+\left[\begin{array}{c}
F_{1} \\
F_{2} \\
F_{3} \\
T_{1} \\
T_{2} \\
T_{3}
\end{array}\right]
$$

where:

- $\quad F_{x}, F_{y}$, and $F_{z}$ are the translational force components

- $T_{x}, T_{y}$, and $T_{z}$ are the rotational force components

- $K_{i i}$ are the stiffness coefficients

- $\quad x, y$, and $z$ are the translational displacements

- $\quad a, b$, and $c$ are the rotational displacements

- $C_{i i}$ are the damping coefficients

- $\quad V_{x}, V_{y}$, and $V_{z}$ are time derivatives of $x, y$, and $z$

- $\quad \omega_{x}, \omega_{y}, \omega_{z}$ are time derivatives of $a, b$, and $c$

- $\quad F_{1}, F_{2}$, and $F_{3}$ are preload forces

- $T_{1}, T_{2}$, and $T_{3}$ are preload torques

Similarly, a spring-damper element was used in the actuator assembly is defined by the following:

$$
F_{S}=-C\left(\frac{d r}{d t}\right)-K(r-l)+F_{1}
$$

where:

- $F_{s}$ is the acting force

- $\quad C$ is the viscous damping coefficient

- $K$ is the stiffness coefficient

- $\quad r$ represents the distance between the connection points of the spring-damper

- $l$ is the reference length

- $\quad F_{1}$ defines the preload force of the spring

The parameters for the flexible connections and contact forces used in the scissor lift model are shown in Table 5. For the wheel to road contact, stiffness was determined by measuring deflection of the wheels for a fully loaded lift. For the fully loaded lift (13925 $\mathrm{N}$ ), the average measured wheel deflection was $2.5 \mathrm{~mm}$. This results in a wheel to road contact stiffness of $1392 \mathrm{kN} / \mathrm{m}$ as shown in Table 5 . Since the wheels are rigidly connected to the base and cannot roll, a small coefficient of friction was applied to allow 
movement of the scissor lift. The solid-to-solid contact between the front wheels and curb were assumed to have to same parameters as the wheel to road contact. As mentioned earlier, a solid-to-solid contact made between the pothole protection device and the leading edge of the pothole in road. The stiffness of this contact was estimated based on comparison of the modeling response of the pothole depression test with the experimental response. An average coefficient of friction for a steel-to-steel contact (0.30-0.35) was used for this contact.

The four connections made between the scissor assembly and the base of the lift provide the major stiffness and damping of the scissor structure. It is emphasized the values for these connections, shown in Table 5, are not representative of the actual connections but rather characterize the equivalent stiffness and damping of the scissor lift. The stiffness and damping values of these connections were determined by comparing the modeling and experimental responses for the previously mentioned curb impact and pothole depression tests. From the curb impact test, a pitch motion (around Y-axis) was primarily observed. This pitch motion was primarily influenced by the vertical (Z-axis) stiffness and damping of the bushing elements and the solid-to-solid contacts between the outer scissor frame and base. Once these parameters were determined from the curb impact test, the modeling response was compared to the experimental response for a pothole depression test for further validation. The pothole depression test produced a combined pitch, rolling, and bouncing motion. The modeling response for this test was similar to the experimental response, so the lumped parameters of these connections (ID $4 \& 6$ ) were considered to be adequate for future simulations. 
Table 5: Major flexible connections and their major parameters

\begin{tabular}{|c|c|c|c|c|c|c|c|c|}
\hline \multicolumn{2}{|r|}{ Connection } & \multirow{2}{*}{$\begin{array}{l}\text { ADAMS } \\
\text { Constraint } \\
\text { Element }\end{array}$} & \multicolumn{6}{|c|}{ Major Parameters } \\
\hline ID & Location & & $\begin{array}{c}\mathrm{k} \\
(\mathrm{N} / \mathrm{m}) \\
\end{array}$ & $\begin{array}{c}c \\
(\mathrm{~N}-\mathrm{s} / \mathrm{m}) \\
\end{array}$ & $\begin{array}{c}\text { Force } \\
\text { Exponent }\end{array}$ & $\begin{array}{c}\text { Penetration } \\
\text { Depth } \\
(\mathrm{mm})\end{array}$ & $\mu_{\text {static }}$ & $\mu_{\text {dynamic }}$ \\
\hline 1 & $\begin{array}{l}\text { Wheel to } \\
\text { Road }\end{array}$ & $\begin{array}{l}\text { Solid-to-Solid } \\
\text { Contact }\end{array}$ & $1.39 \mathrm{E}+06$ & $1.00 \mathrm{E}+04$ & 1.5 & 2.5 & 0.04 & 0.03 \\
\hline 2 & $\begin{array}{l}\text { Wheel to } \\
\text { Curb }\end{array}$ & $\begin{array}{l}\text { Solid-to-Solid } \\
\text { Contact }\end{array}$ & $1.39 \mathrm{E}+06$ & $1.00 \mathrm{E}+04$ & 1.5 & 2.5 & 0.04 & 0.03 \\
\hline 3 & $\begin{array}{l}\text { Pothole } \\
\text { Protection } \\
\text { device to } \\
\text { Road }\end{array}$ & $\begin{array}{l}\text { Solid-to-Solid } \\
\text { Contact }\end{array}$ & $1.00 \mathrm{E}+07$ & $2.00 \mathrm{E}+05$ & 2.2 & 0.1 & 0.35 & 0.30 \\
\hline 4 & $\begin{array}{l}\text { Outer Scissor } \\
\text { Frame } 1 \\
\text { Roller to Base }\end{array}$ & $\begin{array}{l}\text { Solid-to-Solid } \\
\text { Contact }\end{array}$ & $1.18 \mathrm{E}+06$ & $8.00 \mathrm{E}+03$ & 1.2 & 0.1 & 0.04 & 0.03 \\
\hline 5 & $\begin{array}{l}\text { Outer Scissor } \\
\text { Frame } 4 \\
\text { Roller to } \\
\text { Platform }\end{array}$ & $\begin{array}{l}\text { Solid-to-Solid } \\
\text { Contact }\end{array}$ & $1.00 \mathrm{E}+06$ & $5.00 \mathrm{E}+03$ & 2.2 & 0.1 & 0.04 & 0.03 \\
\hline & & & $\begin{array}{c}\text { Trans. } \\
\mathrm{k} \\
(\mathrm{N} / \mathrm{m}) \\
\end{array}$ & $\begin{array}{c}\begin{array}{c}\text { Rot. } \\
k \\
(\mathrm{~N}-\mathrm{m} / \mathrm{deg})\end{array} \\
\end{array}$ & $\begin{array}{c}\text { Trans. } \\
\text { c } \\
(\mathrm{N}-\mathrm{s} / \mathrm{m})\end{array}$ & $\begin{array}{c}\text { Rot. } \\
\mathrm{c} \\
(\mathrm{N}-\mathrm{ms} / \mathrm{deg}) \\
\end{array}$ & $\begin{array}{l}\text { Trans. } \\
\text { Preload } \\
(\mathrm{N})\end{array}$ & $\begin{array}{l}\text { Rot. } \\
\text { Preload } \\
(\mathrm{N}-\mathrm{m}) \\
\end{array}$ \\
\hline \multirow{3}{*}{6} & \multirow{3}{*}{$\begin{array}{l}\text { Inner Scissor } \\
\text { Frame } 1 \text { to } \\
\text { Base }\end{array}$} & Bushing - X & $4.00 \mathrm{E}+6$ & 0.05 & $1.00 \mathrm{E}+5$ & 0.0005 & 0 & 0 \\
\hline & & Bushing - Y & $4.00 \mathrm{E}+5$ & 0.05 & $2.00 \mathrm{E}+4$ & 0.0005 & 0 & 0 \\
\hline & & Bushing - Z & $1.18 \mathrm{E}+6$ & 0.10 & $8.00 \mathrm{E}+3$ & 0.0010 & 0 & 0 \\
\hline 7 & $\begin{array}{l}\text { Actuator } \\
\text { boom to } \\
\text { cylinder } \\
\text { pseudo piston }\end{array}$ & $\begin{array}{l}\text { Spring- } \\
\text { damper }\end{array}$ & $9.00 \mathrm{E}+7$ & & $4.00 \mathrm{E}+4$ & & 0 & \\
\hline
\end{tabular}

The spring-damper connection between actuator boom and pseudo piston allows a bouncing motion of the scissor structure to be achieved. In this mechanical equivalent model of a hydraulic actuator, the parameters of the spring-damper connection were estimated and calibrated by comparing the simulated bouncing response (z-axis) with the corresponding experimental response from the curb impact test. The parameters for the spring-damper element are shown in Table 5. As expected, the actuator has a high equivalent stiffness and damping. 
3.7 Solution of the Equations of Motion

Fig. 9 shows a two-dimensional diagram of the outer scissor frame 1. The planar equations of motion for the outer scissor frame are as follows:

$$
\begin{aligned}
& \mathrm{kx}_{\mathrm{X}}(\mathrm{X} 1-\mathrm{XB})+\mathrm{c}_{\mathrm{X}}\left(\mathrm{X} 1^{\prime}-\mathrm{XB}\right)+\mathrm{F}_{21 \mathrm{X}}+\mathrm{F}_{\mathrm{ACT} 1 \mathrm{X}}+\mathrm{F}_{41 \mathrm{X}}=\mathrm{m} 1 \mathrm{X} 1^{\prime \prime} \\
& \mathrm{k}_{\mathrm{Z}}(\mathrm{Z} 1-\mathrm{ZB})+\mathrm{c}_{\mathrm{Z}}\left(\mathrm{Z} 1^{\prime}-\mathrm{ZB}^{\prime}\right)+\mathrm{F}_{21 \mathrm{Z}}+\mathrm{F}_{\mathrm{ACT} 1 \mathrm{Z}}+\mathrm{F}_{41 \mathrm{Z}}=\mathrm{m} 1 \mathrm{Z} 1^{\prime \prime} \\
& \mathrm{T}_{\mathrm{s}}+\left(\mathrm{k}_{\mathrm{Z}}(\mathrm{Z} 1-\mathrm{ZB})\right)\left(\mathrm{l}_{11} \cos \theta_{1}\right)+\left(\mathrm{c}_{\mathrm{Z}}\left(\mathrm{Z} 1^{\prime}-\mathrm{ZB}^{\prime}\right)\right)\left(\mathrm{l}_{11} \cos \theta_{1}\right)-(\mathrm{kx}(\mathrm{X} 1-\mathrm{XB}))\left(\mathrm{l}_{11} \sin \theta_{1}\right)- \\
& \left(\mathrm{c}_{\mathrm{X}}\left(\mathrm{X} 1^{\prime}-\mathrm{XB}\right)\right)\left(\mathrm{l}_{11} \sin \theta_{1}\right)+\mathrm{F}_{21 \mathrm{Z}}\left(\mathrm{l}_{12} \cos \theta_{1}\right)-\mathrm{F}_{21 \mathrm{X}}\left(\mathrm{l}_{12} \sin \theta_{1}\right)-\mathrm{F}_{\mathrm{ACT} 1 \mathrm{Z}}\left(\mathrm{l}_{13} \cos \theta_{1}\right)+ \\
& \mathrm{F}_{\mathrm{ACT} 1 \mathrm{X}}\left(\mathrm{l}_{13} \sin \theta_{1}\right)-\mathrm{F}_{41 \mathrm{Z}}\left(\mathrm{l}_{14} \cos \theta_{1}\right)+\mathrm{F}_{41 \mathrm{X}}\left(\mathrm{l}_{14} \sin \theta_{1}\right)=\mathrm{I}_{\mathrm{Y} 1} \alpha
\end{aligned}
$$

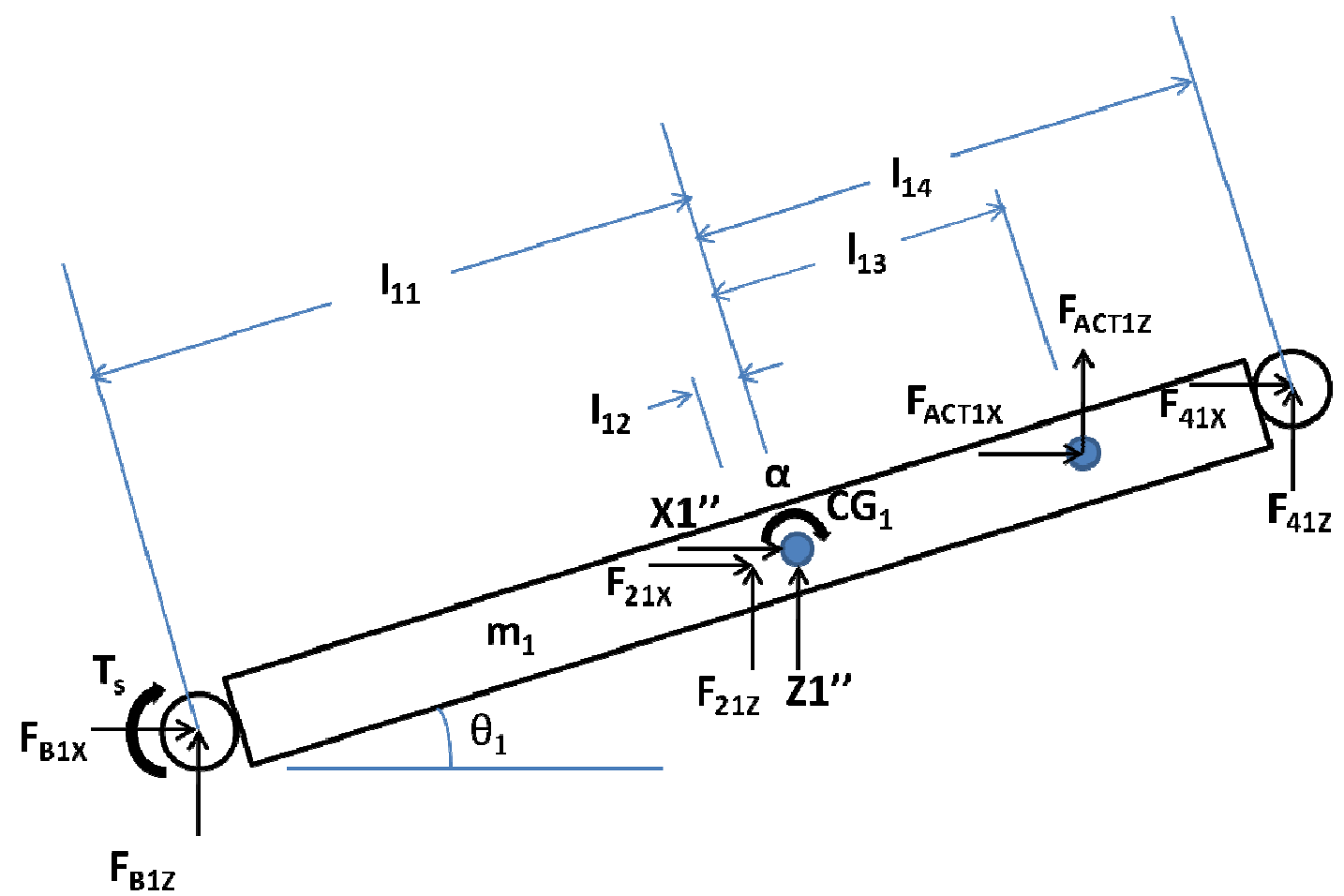

Fig. 9: Two-dimensional diagram of inner scissor frame 1

$\mathrm{ADAMS}^{\circledR}$ formulates the differential equations of motion, similar to those in eq. (16-18), for the entire system as: 


$$
M \ddot{q}+\Phi_{q}^{T} \lambda-A^{T} F(q, \dot{q})=0
$$

where:

- $\quad M$ is the mass matrix

- $F$ is the set of applied forces and gyroscopic terms of the inertia forces

- $A^{T}$ is the matrix that projects the applied forces in the direction $q$

- and $\Phi_{q}^{T}$ is the gradient of the constraints at any given state.

Combined, the algebraic kinematic constraint equations (4) and the differential equation of motions (19) form the equations of motion for a constrained body. In order to obtain a unique solution in dynamic analysis, equations (4) and (16) are considered together along with the appropriate initial conditions (Nikravesh, 1988). These differential-algebraic equations (DAEs) can be solved by various numerical integration techniques.

The default numerical integrator in Adams/C++ Solver, GSTIFF, was used for the dynamic analysis of the scissor lift model. The GSTIFF integrator is based on BackwardDifference Formulae (BDF) and is a variable-order, variable-step, multi-step integrator (REF Adams). Two phases, prediction and correction, are needed to numerically determine a solution to the system. At each new step in the integration, a polynomial of a specified order is fitted to past values of the system state, which is then extrapolated to the present time for the prediction. The GSTIFF integrator uses a Taylor series algorithm to perform the prediction. Since only past values are used in the prediction phase, the equations of motion are not guaranteed to be satisfied. Rather, the prediction phase provides an initial guess to be used in the correction phase.

The correction phase uses BDFs to relate to the derivative of the states at the current time to the values of these states. A common first-order BDF, the Backward Euler integrator, is described in the following equation:

$$
y_{n+1}=y_{n}+h \dot{y}_{n+1}(20)
$$


where:

- $y_{n+1}$ is the solution being calculated

- $y_{n}$ is the solution calculated at $\mathrm{t}=\mathrm{t}_{\mathrm{n}}$

- and $h$ is the step size of the integration.

From equation (20), the following relationship can be determined:

$$
\Delta \dot{y}=\frac{1}{\mathrm{~h}} \Delta \mathrm{y}(21)
$$

In order to apply equation (20) to system, equations (4) and (19) must be converted to first-order form. This is accomplished by introducing a velocity variable $u$, which is defined as:

$$
u-\dot{q}=0(22) \text {. }
$$

Substituting equation (22) into (19), the first-order form of the equations of motion can be described as:

$$
\begin{gathered}
M \dot{u}+\Phi_{\mathrm{q}}^{\mathrm{T}} \lambda-\mathrm{A}^{\mathrm{T}} F=0(23) \\
u-\dot{q}=0(24) \\
\Phi=0(25) .
\end{gathered}
$$

The Jacobian matrix of equation (23) is determined by applying a BDF (equation 21) to the first-order DAEs of the system and can be expressed as:

$$
\left[\begin{array}{ccc}
\frac{M}{h \beta_{0}}-A^{T} F_{U} & M_{q} \dot{u}+\Phi_{\mathrm{qq}}^{\mathrm{T}} \lambda-\left(\mathrm{A}^{\mathrm{T}} \mathrm{F}\right) & \Phi_{q}^{T} \\
I & -\frac{I}{h \beta_{0}} & 0 \\
0 & \Phi_{\mathrm{q}} & 0
\end{array}\right](26)
$$

where:

- $\quad h$ is the step size

- $\beta_{0}$ is a scalar that is characteristic to the integration order

A quasi-Newton-Raphson algorithm is used to solve the difference equation and obtain the values of the state variables. Unlike the algorithm used in the predictor phase, this 
algorithm ensures the equations of motion and constraint are satisfied. The Jacobian matrix (26) is used at each iteration to calculate the corrections to the states.

\subsection{Simulations}

Instability of a scissor lift can result from a number of conditions. For instance, worker generated forces acting on lift during high winds could produce instability. While it is unrealistic to simulate every potential hazardous condition, idealized scenarios can be performed. For this study, tip-over or rollover thresholds were determined for the following scenarios: road slope rollover, rollover due to an applied lateral force, tip-over from a curb impact, and rollover as a result of pothole impact. These simulations were performed for the maximum lift height $(5.8 \mathrm{~m})$ and at the rated platform load $(250 \mathrm{~kg})$. In addition, simulations were performed using test data from an experimental manikin drop test. For these simulations, the platform was not loaded to be consistent with the actual tests.

In order to understand the effects of lift flexibility on its stability, the vertical (z-axis) stiffness and damping of the two bushing elements connecting the scissor assembly to the base were varied from 0.2 to 10 times their empirical values for all scenarios. Also, the stiffness and damping of the two contacts between scissor assembly and the base were varied on the same scale. The stiffness ratio was defined as the following:
S.R. $=\frac{\text { input stiffness }}{\text { empirical stiffness }}$

A stiffness ratio greater than one results in increased rigidity, whereas a stiffness ratio less than one provides more flexibility. The empirical values for these connections (ID 4 \& 6) are shown in Table 5. As previously mentioned, these connections represent the 
lumped flexibility characteristics of the scissor lift, so the other connections' parameter values remained constant for the simulations. Due to the change in the $\mathrm{CG}$ of the lift by varying the stiffness, the maximum platform height was maintained by controlling the motion of the pseudo piston.

It is possible the scissor lift could be improperly used on a sloped surface.

Additionally, the ground surface could compact due to the pressure of the lift, resulting in an uneven ground condition. In order to determine the stability of the scissor lift on a sloped condition, a tilt table simulation was performed. Once the scissor lift was raised to full height and achieved static equilibrium, the level road surface was slowly rotated $(0.2 \mathrm{deg} / \mathrm{sec})$ around the $\mathrm{X}$-axis until the wheels on the high side of the lift lost contact with the road. The angle at which this occurs is referred to as the slope rollover threshold. To prevent the lift from lateral sliding during the road surface rotation, a high coefficient of friction was assigned to wheel to road contact (ID 1).

Various worker actions produce external forces on a scissor lift. Most often these forces are applied to the platform or surrounding guardrail, since the worker performs his/her tasks within this area. The stability of the scissor lift under a lateral load was simulated by applying a lateral force (Y-direction) at mid-span on the top guardrail. The lateral force rollover threshold was determined by increasing this force until rollover occurred.

As part of the dynamic modeling of the scissor lift, a standardized direct curb impact test (ISO 16368) was simulated for a fully elevated lift. For this simulation, the front wheels of the scissor lift simultaneously impact a curb as the scissor lift is traveling in the X-direction. The speed of the lift was increased until a tip-over occurred. The speed 
resulting in a tip-over was termed the curb impact speed threshold. Also, a standardized pothole depression test (ISO 16368) was simulated using the scissor lift model. In this test scenario, the scissor lift is driven into a pothole. The right front wheel of the scissor lift drops into the pothole while the pothole protection device impacts the leading edge of the pothole. The pothole protection device's height from the ground surface was increased until rollover occurred. This event was defined as the rollover threshold of the pothole protection device height.

Last, a manikin drop test was simulated using experimental force data. Load cell data from $1.83 \mathrm{~m}$ and $3.35 \mathrm{~m}$ manikin drop tests, shown in Fig. 8, were imported into ADAMS as spline data elements. Next, these splines were applied as a force along the negative Zaxis at mid-span of the top-rail. As shown in the experimental drop tests, the scissor lift did not tip-over. However, a pitch motion was observed and the wheels of the scissor lift lost contact with the ground surface. For an assessment of instability, the lifting height of a rear wheel was measured during the simulations. 


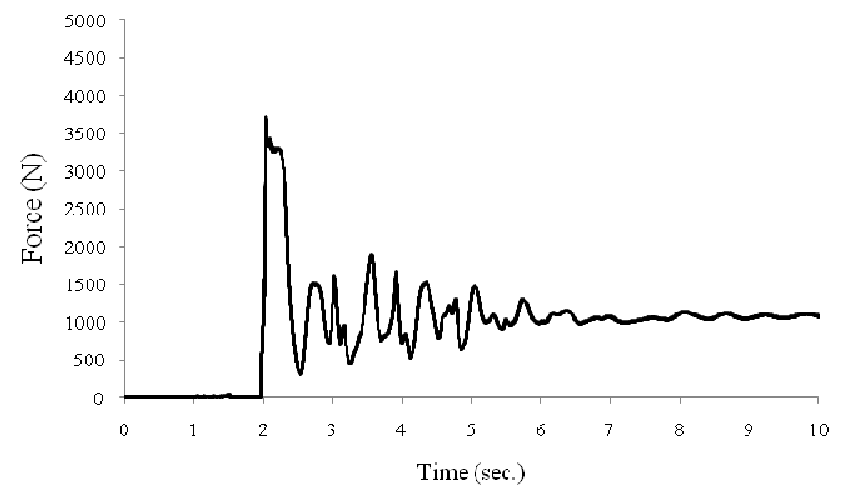

(a)

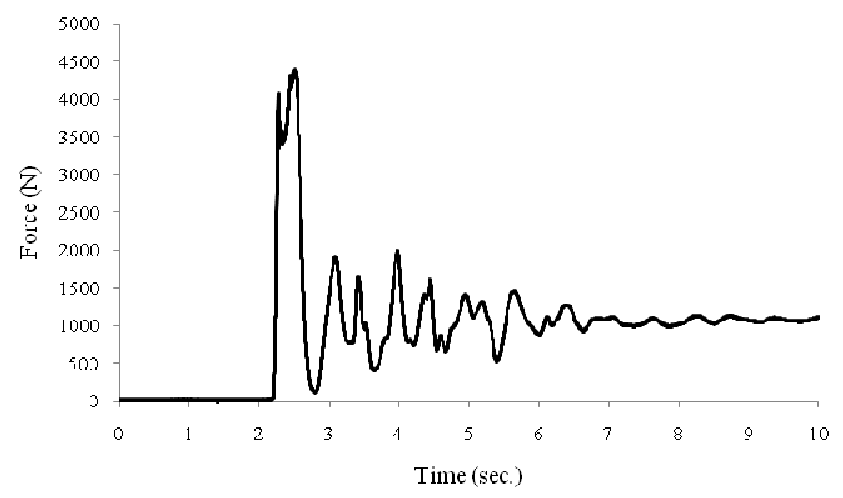

(b)

Fig. 10: Measured load cell data from manikin drop tests: (a) $1.83 \mathrm{~m}$ drop height (b) 3.35 $\mathrm{m}$ drop height 


\section{Chapter 4: Results}

\subsection{Model Calibration/Validation}

Although the individual components of the model were based on manufacturer drawings, further validation was necessary before simulations could be performed. For a static validation, the center of gravity $(\mathrm{CG})$ of the model was compared with the $\mathrm{CG}$ from experimental testing, as shown in Table 5. Due to height limitations of the testing facility, the maximum lift height evaluated in the testing was $3.052 \mathrm{~m}$. The simulated

Table 6: Comparison of the center of gravity (CG) of the scissor lift model and that measured in an experiment (Ronaghi et al., 2009).

\begin{tabular}{|c|c|c|c|c|c|c|c|c|c|}
\hline \multirow{2}{*}{$\begin{array}{l}\qquad \text { Lift } \\
\text { Height }(\mathrm{m})\end{array}$} & \multicolumn{3}{|c|}{$\begin{array}{c}\text { Measured } \\
\text { center of gravity }(\mathrm{m})\end{array}$} & \multicolumn{3}{|c|}{$\begin{array}{c}\text { Simulated model } \\
\text { center of gravity }(\mathrm{m})\end{array}$} & \multicolumn{3}{|c|}{$\begin{array}{c}\text { Percent } \\
\text { Difference }\end{array}$} \\
\hline & $X_{C G}$ & $\mathrm{Y}_{\mathrm{CG}}$ & $Z_{C G}$ & $X_{C G}$ & $\mathrm{Y}_{\mathrm{CG}}$ & $Z_{C G}$ & $X_{C G}$ & $Y_{C G}$ & $\mathrm{Z}_{\mathrm{CG}}$ \\
\hline 0.998 & 0.042 & 0.000 & 0.468 & 0.042 & 0.000 & 0.482 & 0.0 & 0.0 & 3.0 \\
\hline 1.530 & 0.039 & 0.002 & 0.623 & 0.039 & 0.000 & 0.632 & 0.0 & 0.2 & 1.4 \\
\hline 2.155 & 0.034 & 0.003 & 0.801 & 0.034 & 0.000 & 0.807 & 0.0 & 0.4 & 0.7 \\
\hline 3.052 & 0.021 & 0.006 & 1.052 & 0.021 & 0.000 & 1.059 & 0.0 & 0.7 & 0.7 \\
\hline
\end{tabular}

model's longitudinal component of the $\mathrm{CG}\left(\mathrm{X}_{\mathrm{CG}}\right)$ is identical to the experimental $\mathrm{X}_{\mathrm{CG}}$ for all lift heights examined. Also, the vertical component of the $\mathrm{CG}\left(\mathrm{Z}_{\mathrm{CG}}\right)$ is similar for the model and measured values. A maximum difference of $3.0 \%$ for the $\mathrm{Z}_{\mathrm{CG}}$ was observed at the stowed position $(0.998 \mathrm{~m})$ and this difference decreased to $0.7 \%$ at the maximum height examined $(3.052 \mathrm{~m})$. As a result of symmetry, the lateral component of the CG $\left(\mathrm{Y}_{\mathrm{CG}}\right)$ of the simulated model is zero for all heights and nearly zero for the measured results. The maximum difference for the $\mathrm{Y}_{\mathrm{CG}}$ was found to be $0.7 \%$, which occurred at the maximum height considered $(3.052 \mathrm{~m})$. While a direct comparison could not be made 
for elevated heights above $3.052 \mathrm{~m}$, the results suggest the simulated model's CG would be nearly the same as the actual lift's CG for additional heights. Therefore, the mass distribution of the model was validated.

Once the geometry and mass distribution of the scissor lift model was validated, the dynamic characteristics of the model were examined. This was accomplished by comparing the acceleration response of the simulated curb impact and pothole depression tests to the corresponding experimental tests. For the simulations, the accelerations were measured at the same location on the main platform as in the experimental tests. Also, the scissor lift was raised to the maximum height $(5.8 \mathrm{~m})$ and traveled at the maximum elevated speed $(0.29 \mathrm{~m} / \mathrm{s})$ to be consistent with the experimental testing. The location of the rated loadings on the platform and extension were the same as the experiment. As mentioned earlier, certain connection parameters were estimated to optimize the modeling responses with the experimental responses. An iterative process of varying stiffness and damping values of the connections and contacts listed in Table 4 resulted in a sufficient agreement of modeling responses with experimental responses. Unlike the experimental test surface, the road surface in the modeling is perfectly smooth. As a result, all of the experimental responses contain more noise than simulation responses. Further, spikes in experimental responses were observed and are likely attributed to the high frequencies of the frame members of the lift. Since the tip-over/rollover of a scissor lift is a low frequency phenomenon, these high frequencies can be neglected.

From, Fig. 9 (a), the curb impact mainly excites a pitch motion of the scissor lift. The resonant pitch frequency (around $1.1 \mathrm{~Hz}$ ) of the model falls within the range observed in 
the experimental tests $(1.08-1.25 \mathrm{~Hz})$. In order to compare the damping, the logarithmic decrement was determined for the simulated and experimental response by the following:

$$
\delta=\frac{1}{n} \ln \frac{x_{1}}{x_{n+1}}
$$

where:

- $\delta$ is the logarithmic decrement

- $\mathrm{n}$ is an integer

- $\mathrm{x}_{1}$ is the amplitude at $\mathrm{t}=\mathrm{t}_{\mathrm{p}}$

- $\mathrm{x}_{\mathrm{n}+1}$ is the amplitude at $\mathrm{t}=\mathrm{t}_{\mathrm{p}}+\mathrm{n} \tau$

- $\tau$ is the period of the cycle

The logarithmic decrement represents the amplitude reduction rate for a free-damped vibration (Rao, 2004). From Fig. 9 (a), the logarithmic decrement for the simulated response was found to be 0.36 , as compared to a logarithmic decrement of 0.24 for the experimental response. Since the simulation produced an exact direct curb impact and the scissor lift is symmetrical about the ZX plane, a lateral response was not observed for the curb impact, as shown in Fig. 9 (b). For the experimental curb impact test, the wheels of the lift may not have contacted the curb at the exact time. Consequently, a lateral response was observed in the experimental curb impact test, shown in Fig. 9 (b). As expected, acceleration peak magnitudes of the lateral response were much smaller than the peaks of the longitudinal response during impact. The experimental direct curb impact test produced a quickly decaying, higher wave frequency $(4.08-6.75 \mathrm{~Hz})$ in the vertical response, which is shown in Fig. 9 (c). This was also observed in the modeling response, also shown in Fig. 9 (c). 

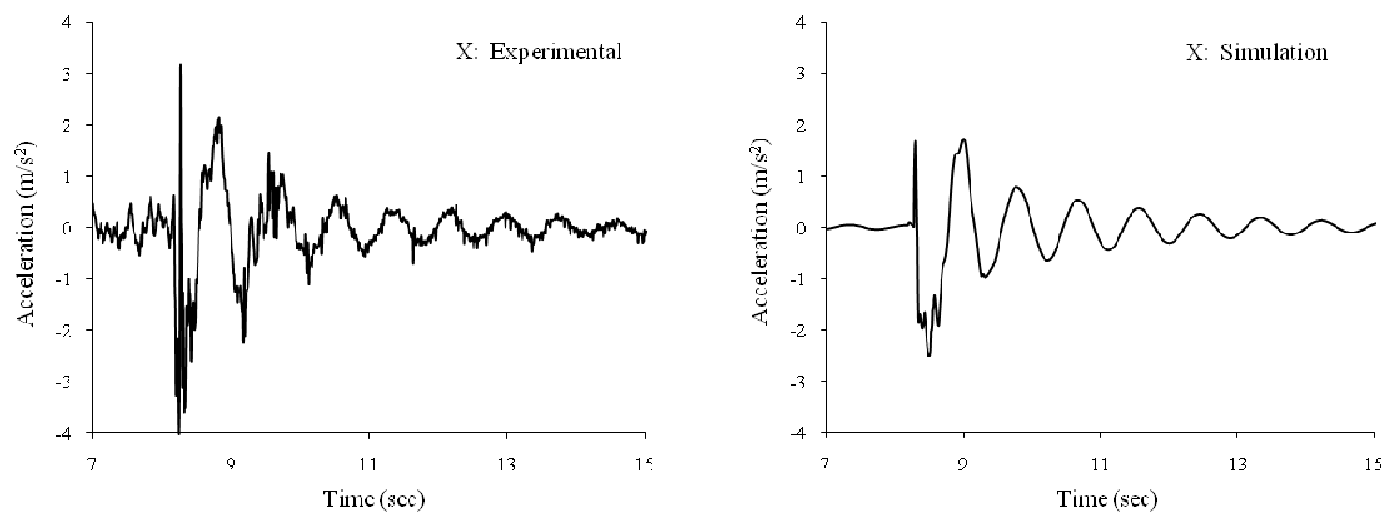

a) Acceleration in the traveling direction (X-axis) of the lift
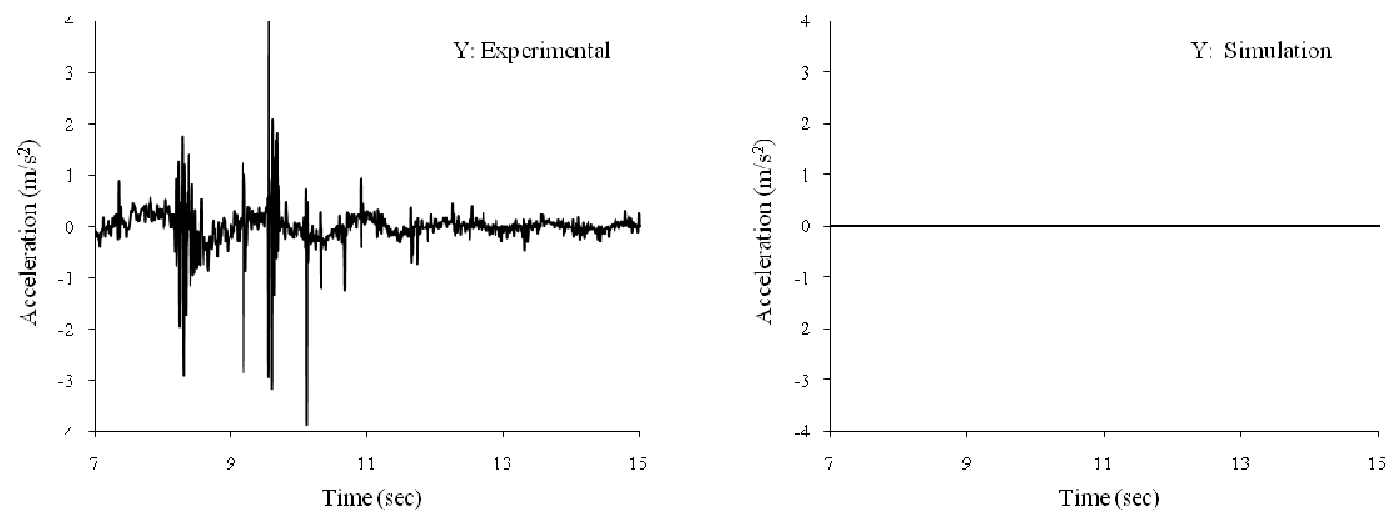

b) Acceleration in the lateral direction (Y-axis) of the lift
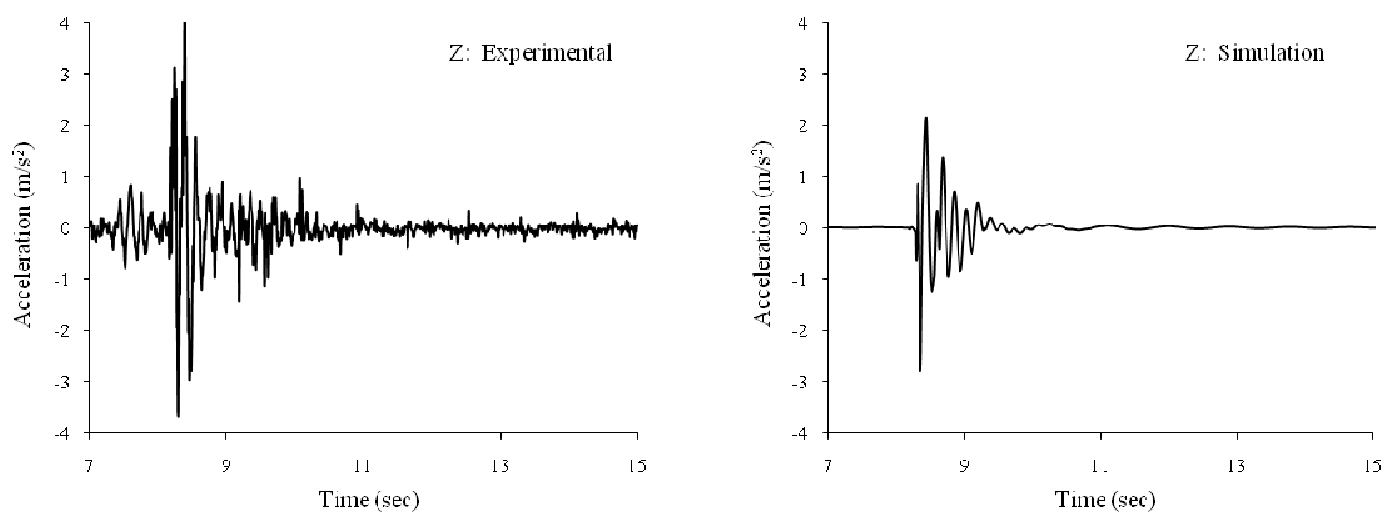

c) Acceleration in the vertical direction (Z-axis) of the lift

Fig. 11: Comparison of the measured accelerations on the main platform (left column) with those predicted from the modeling (right column) for a standardized direct curb impact test. 
To further calibrate the dynamic characteristics of the scissor lift model, the results from a simulated pothole depression test were compared with the corresponding experimental results. Unlike the simulated curb impact test, the pothole depression test produced motion along all three axes. Shown in Fig. 10 (a), the simulated major pitch frequency (around $1.0 \mathrm{~Hz}$ ) was nearly the same as the pitch frequency of the experimental test. The simulated response's peak accelerations were higher than the experimental response's, which could be attributed numerous factors. The exact pothole geometry, contact conditions, and pothole protection device interactions are likely to be different for simulated and experimental tests, resulting in a variation of the peak accelerations. Longitudinally, the logarithmic decrement for the simulated response was estimated to be 0.26 , which is similar to 0.17 for the experimental response. The simulated lateral response resulted in a dominant frequency of $0.58 \mathrm{~Hz}$, which is nearly the same as the experimental lateral resonant frequency of approximately $0.56 \mathrm{~Hz}$, as shown in Fig. 10 (b). Also, the acceleration peak magnitudes and decay trends of these responses are similar. In the vertical direction, the simulated and experimental responses produced a rapidly decaying, random excitation. Therefore, a direct comparison of the bouncing motion could not be made.

With comparison to the responses of the experimental tests, the simulated model's responses agree reasonably well. While certain acceleration peak magnitudes differed for simulated and experimental responses, the dominant frequencies and logarithmic decrements of the responses were similar. Based on these results, the lumped dynamic parameters of the scissor lift model are sufficiently representative of the actual lift's dynamic characteristics. 

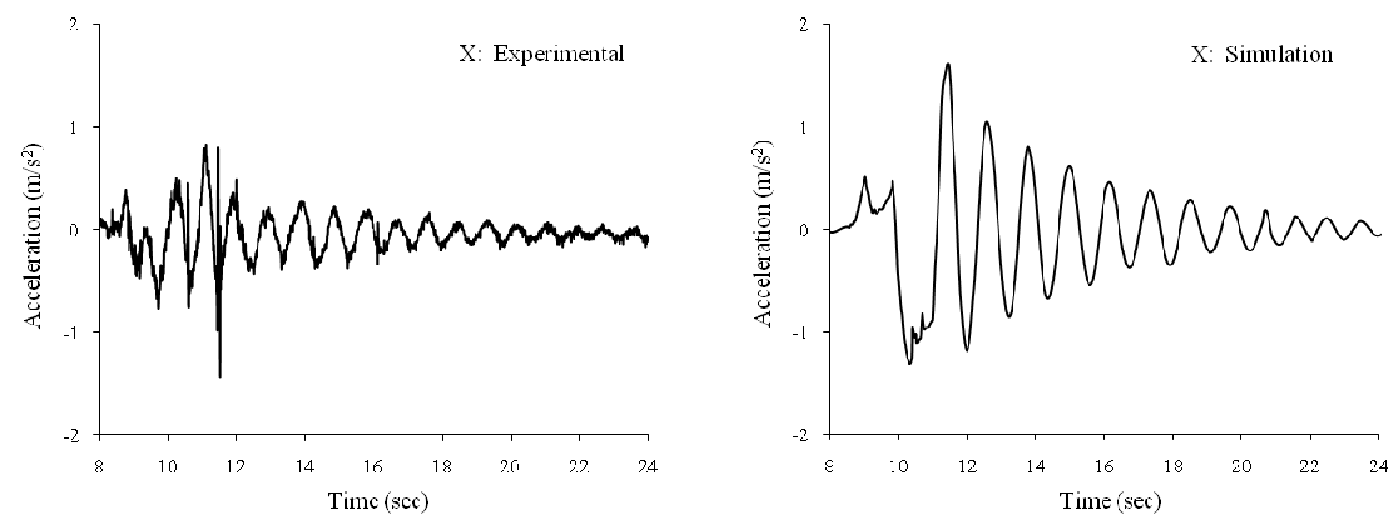

a) Acceleration in the traveling direction (X-axis) of the lift
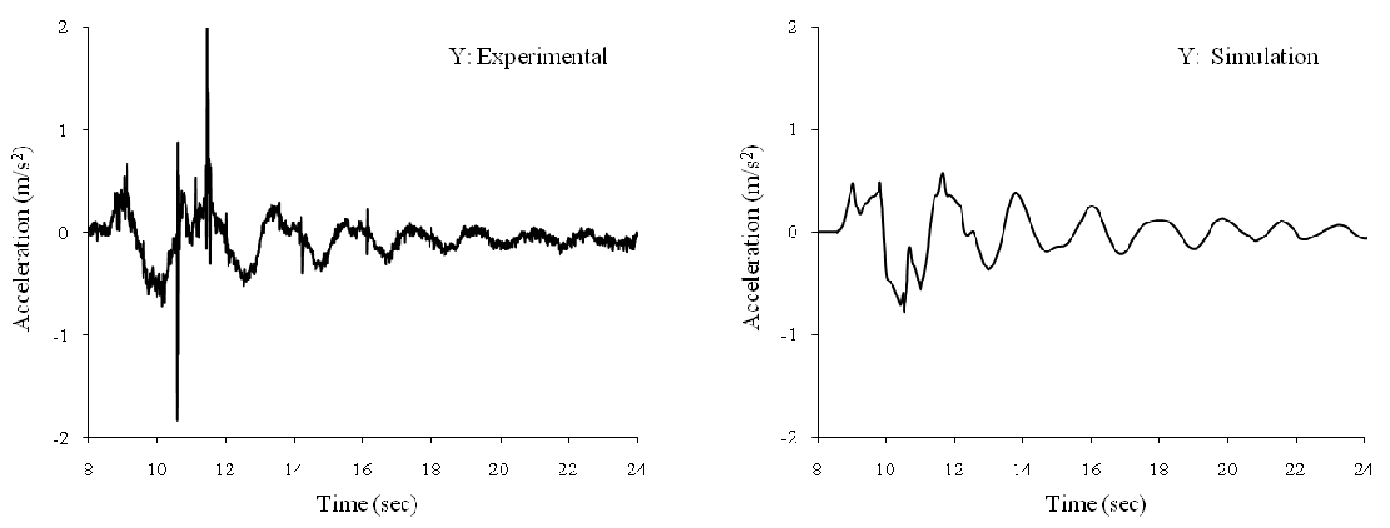

b) Acceleration in the lateral direction (Y-axis) of the lift
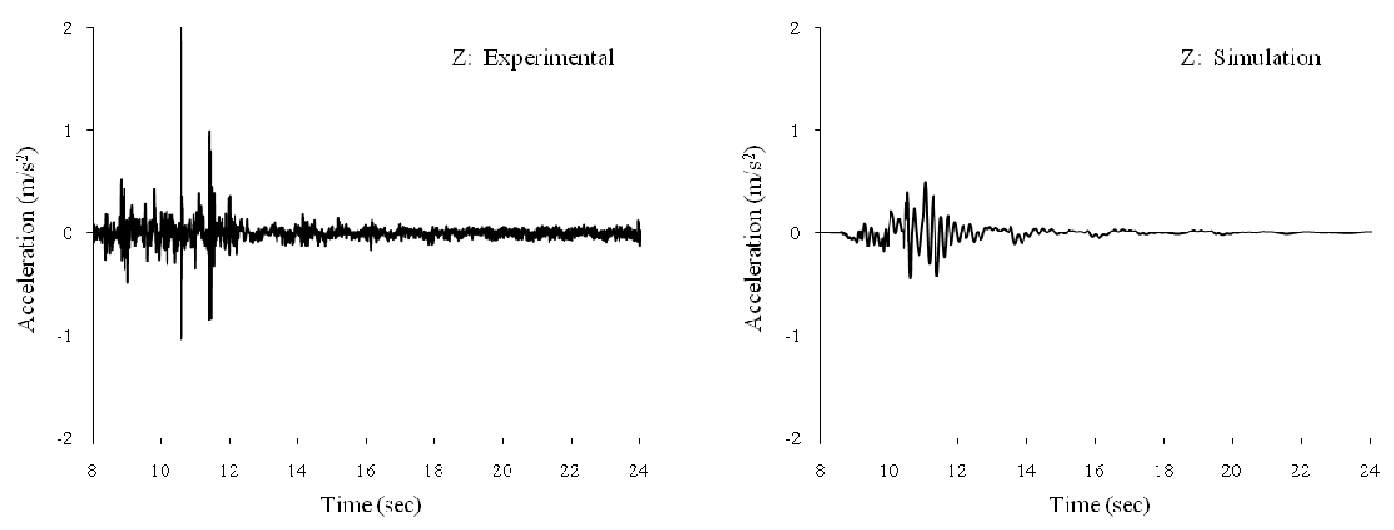

c) Acceleration in the vertical direction (Z-axis) of the lift

Fig. 12: Comparison of the measured accelerations on the main platform (in the left column) with those predicted from the model (in the right column) for the standardized pothole depression test. 


\subsection{Tilting Rollover Threshold}

Fig. 11 shows the scissor lift model performing a tilt table simulation. At the normal stiffness or stiffness ratio of 1 , the slope rollover threshold is approximately $7.21^{\circ}$ as shown in Figure 12.

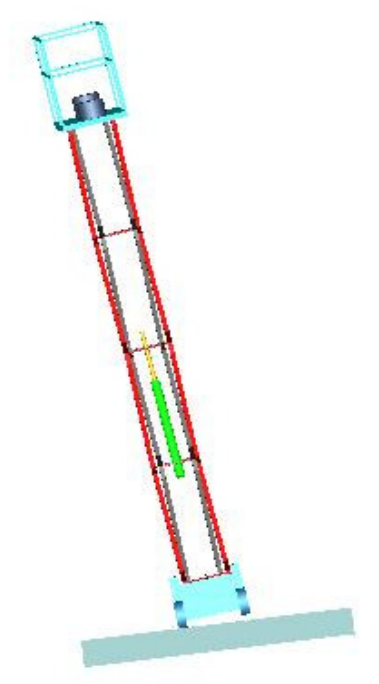

Fig. 13: Tilt table simulation

A decrease in stiffness results in a lower slope rollover threshold and increasing the stiffness provides a larger slope rollover threshold. However, there is a very small variation in the rollover threshold once the stiffness exceeds twice the normal value. At a stiffness ratio of 0.2 , the rollover threshold was found to be $6.55^{\circ}$. The rollover threshold increased up to $7.39^{\circ}$ for a stiffness ratio of 10 . These results are as expected because a reduction in stiffness causes the $\mathrm{CG}$ of the lift to shift toward the tilting direction, thus lowering the rollover threshold. 


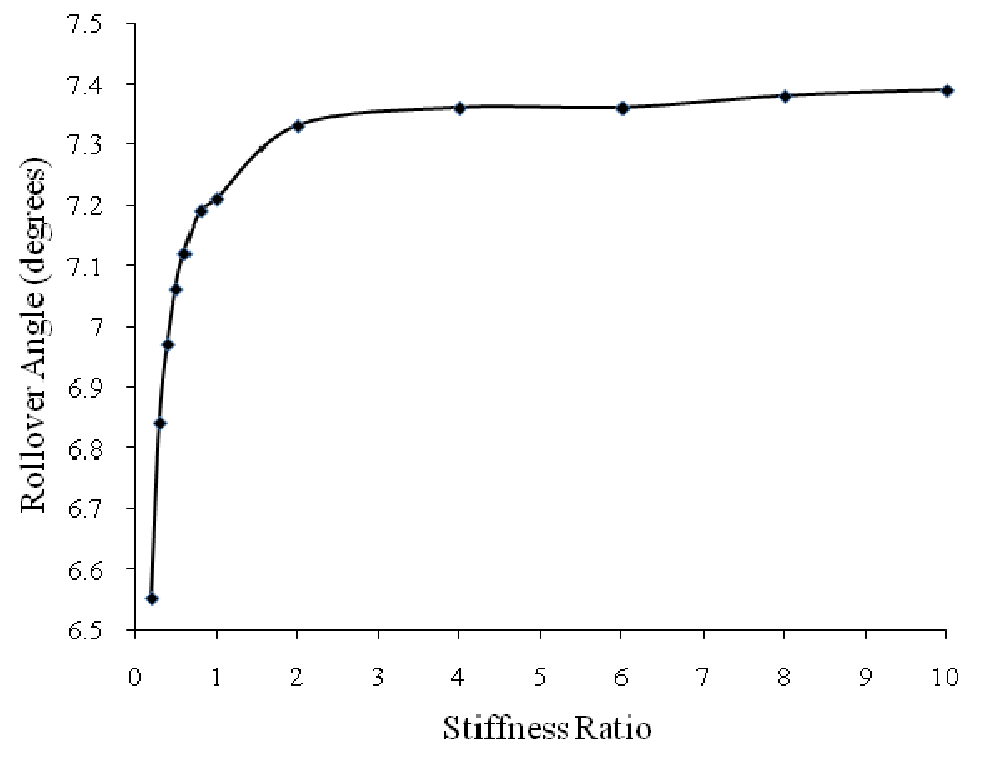

Fig. 14: Effect of the scissor lift structure stiffness on the tilting rollover threshold

\subsection{Lateral Force Rollover Threshold}

The scissor lift model subjected to a lateral force at the guardrail is shown in Fig. 13. The results from the simulations are shown in Fig. 14. The lateral force rollover threshold ranged from $416 \mathrm{~N}$ at a stiffness ratio of 0.2 , to $574 \mathrm{~N}$ for a stiffness ratio of 10 .

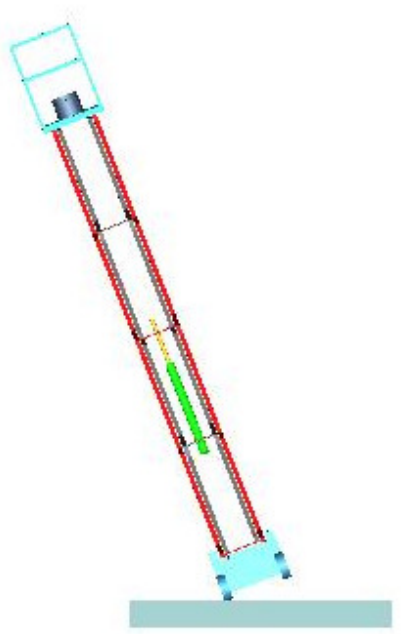

Fig. 15: Lateral force simulation 
At the normal stiffness, a lateral force of $518 \mathrm{~N}(116 \mathrm{lbs})$ is required to cause rollover. This trend is similar to that of the rollover angle threshold and can be attributed to the CG of the lift moving toward the tilting direction with increased flexibility. The results also suggest that using a rigid body model for static rollover calculations would overestimate the stability of the lift.

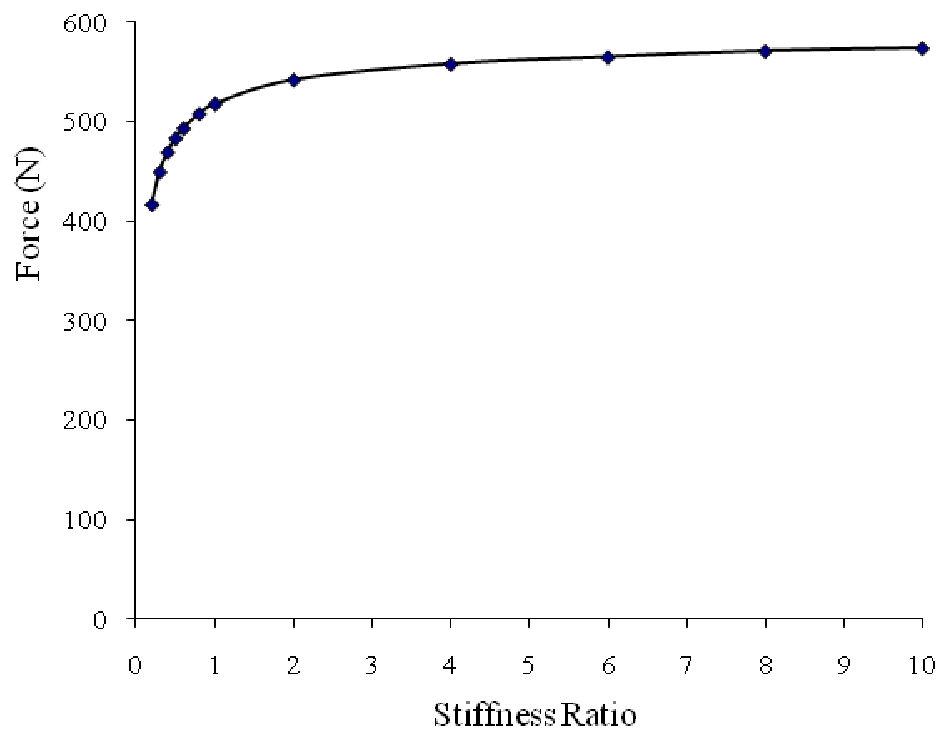

Fig. 16: Effect of the scissor lift's structure stiffness on the rollover threshold due to a lateral force applied to the guardrail.

\subsection{Curb Impact Speed Tip-Over Threshold}

A simulated position of the scissor lift model during a curb impact is shown in Fig. 15. During the curb impact process, some of the scissor lift's kinetic energy is converted to potential energy. Also, some the energy is dissipated through the scissor lift's damping. Standardized analysis only considers the gravitational potential energy, resulting from a change in position of the $\mathrm{CG}$ of the scissor lift, in the calculation of the tip-over speed threshold for a curb impact (ISO 16368). In reality, the potential energy is a combination 


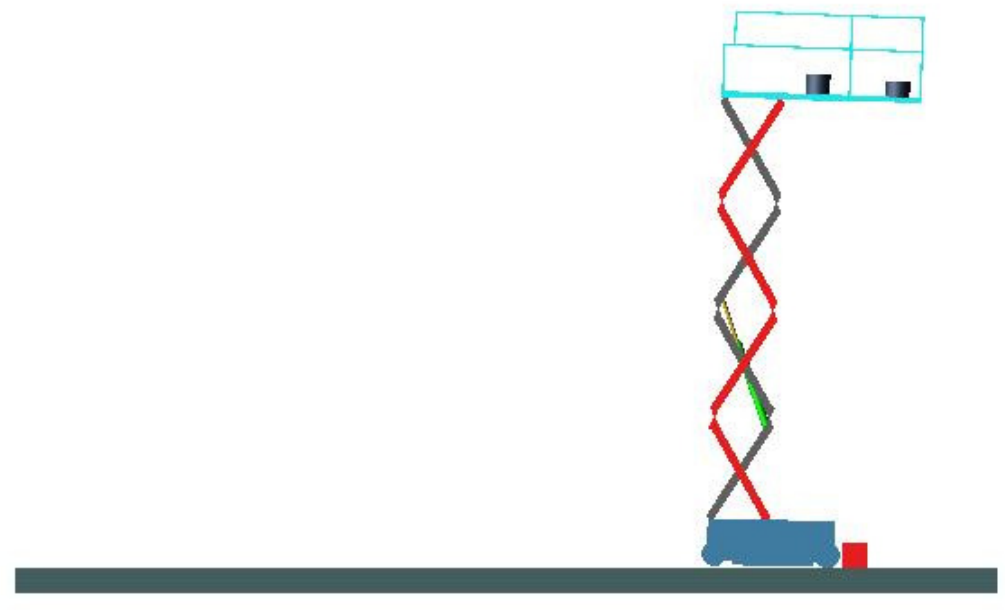

Fig. 17: Simulated curb impact

of the gravitational potential energy and the elastic potential energy of the structure.

Neglecting the deformations due to flexibility of the structures may result in an overestimated threshold from the standardized calculations. The results of the simulated curb impact test are shown in Fig. 16. At the normal stiffness, the tip-over threshold for a curb impact was found to be $1.60 \mathrm{~m} / \mathrm{s}$. From the results, decreasing the stiffness below the normal value did not affect the stability of the lift. An increase in stiffness generally provided a higher tip-over speed threshold for the curb impact. A maximum tip-over speed threshold of $1.72 \mathrm{~m} / \mathrm{s}$ was determined for a stiffness ratio of 10 . Therefore, the results suggest the scissor lift should be as rigid as possible. 


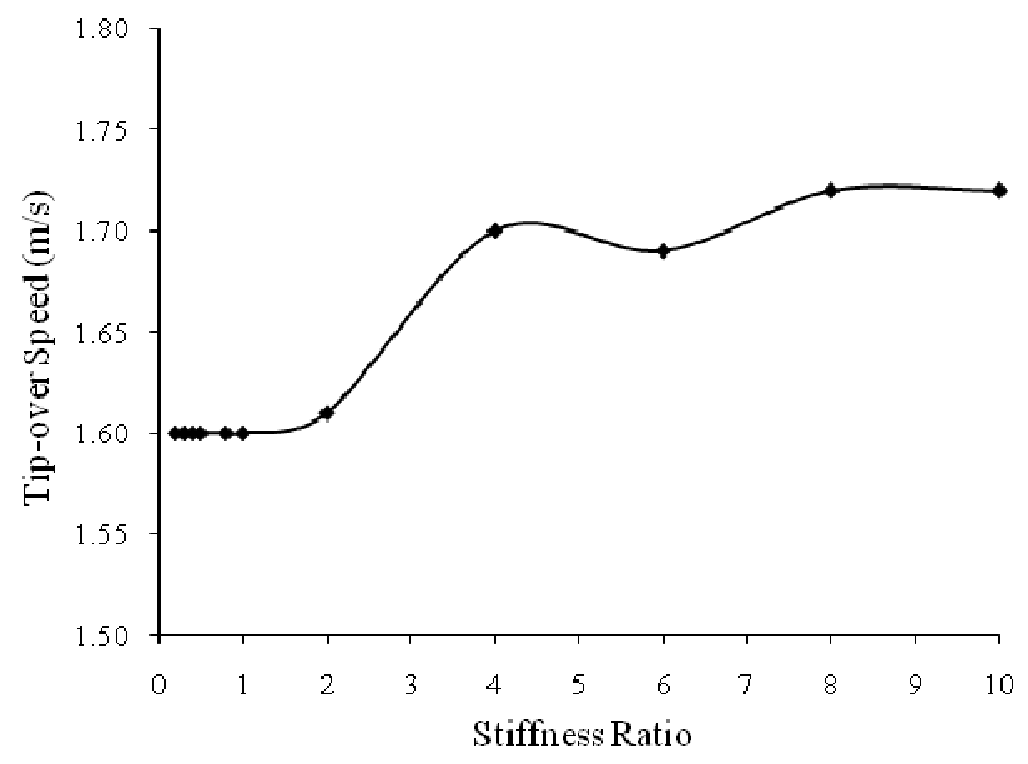

Fig. 18: Effect of the scissor lift structure's stiffness on the tip-over threshold for a curb impact

\subsection{Rollover Threshold based on Pothole Protection Device Height}

The scissor lift simulating a pothole depression test is shown in Fig. 17. In this case, the pothole protection device height was increased until tip-over occurred. From the results in Fig. 18, the scissor lift becomes more unstable with increased flexibility. Once again, the flexibility allows CG of the lift to move toward the unfavorable tipping direction. Therefore, the pothole protection device height must be lower to the ground to provide additional stability. A pothole protection device height less than $21 \mathrm{~mm}$ was needed to prevent rollover for a stiffness ratio of 0.2 . This height could be increased to $28.5 \mathrm{~mm}$ for a rigid scissor lift or stiffness ratio of 10 . In reality, the pothole protection device must maintain clearance with the ground surface while being driven. The results suggest this clearance to be as low as possible to prevent rollovers. 


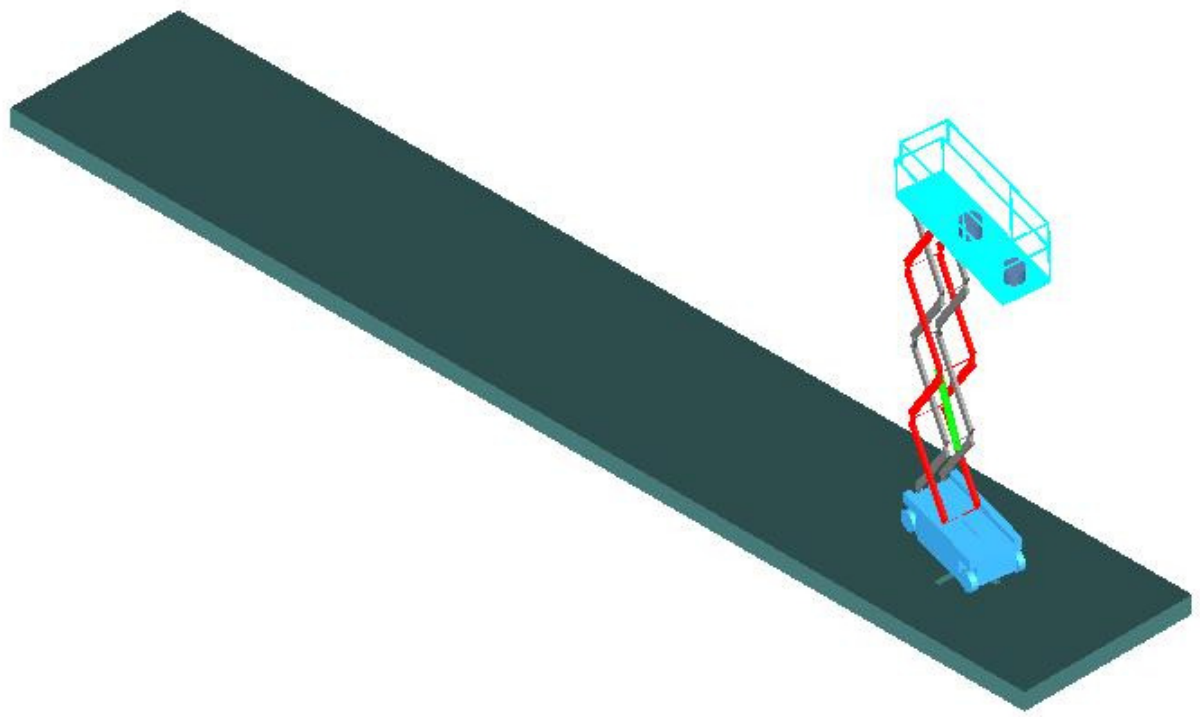

Fig. 19: Simulated pothole depression test

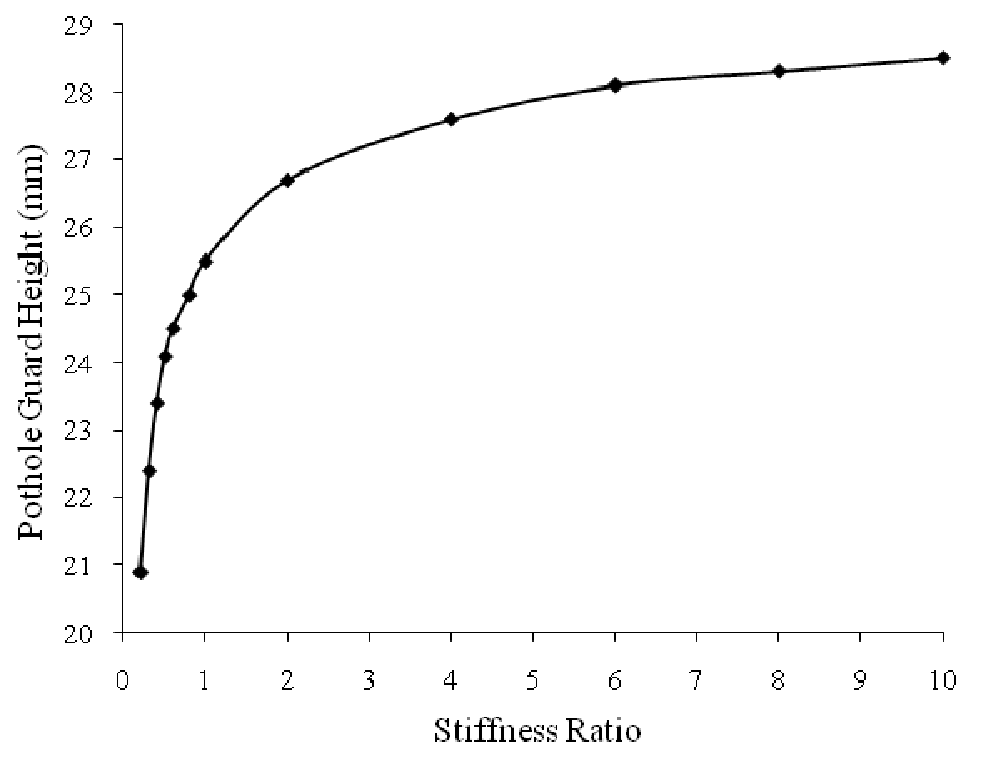

Fig. 20: Effect of the scissor lift structure stiffness on the rollover threshold of the pothole protection device height measured from the ground. 


\subsection{Instability due to Fall Arrest Forces}

During the manikin fall impact, some of energy is absorbed by the scissor lift. The change in potential energy of the lift results in a tipping motion, which is shown in Fig. 19. Consistent with the manikin drop experimental tests, the scissor lift did not tip-over from the application of the fall arrest forces. However, a pitch motion was observed and the rear wheels of the scissor lift lost contact with the ground, which was consistent with the experimental tests. The results from the fall arrest force simulations are shown in Fig. 20. With increased flexibility, the scissor lift became significantly more unstable. An increase in the stiffness marginally improved the stability of the lift. As expected, the $3.35 \mathrm{~m}$ drop produced higher arrest forces than the $1.83 \mathrm{~m}$ drop, which resulted in increased rear wheel lifting.

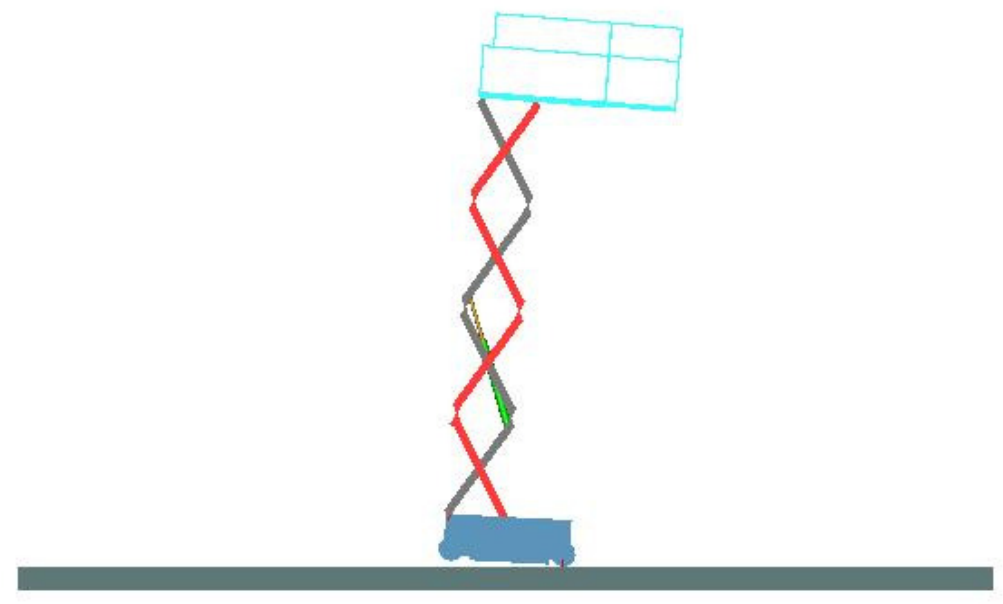

Fig. 21: Fall arrest force simulation 


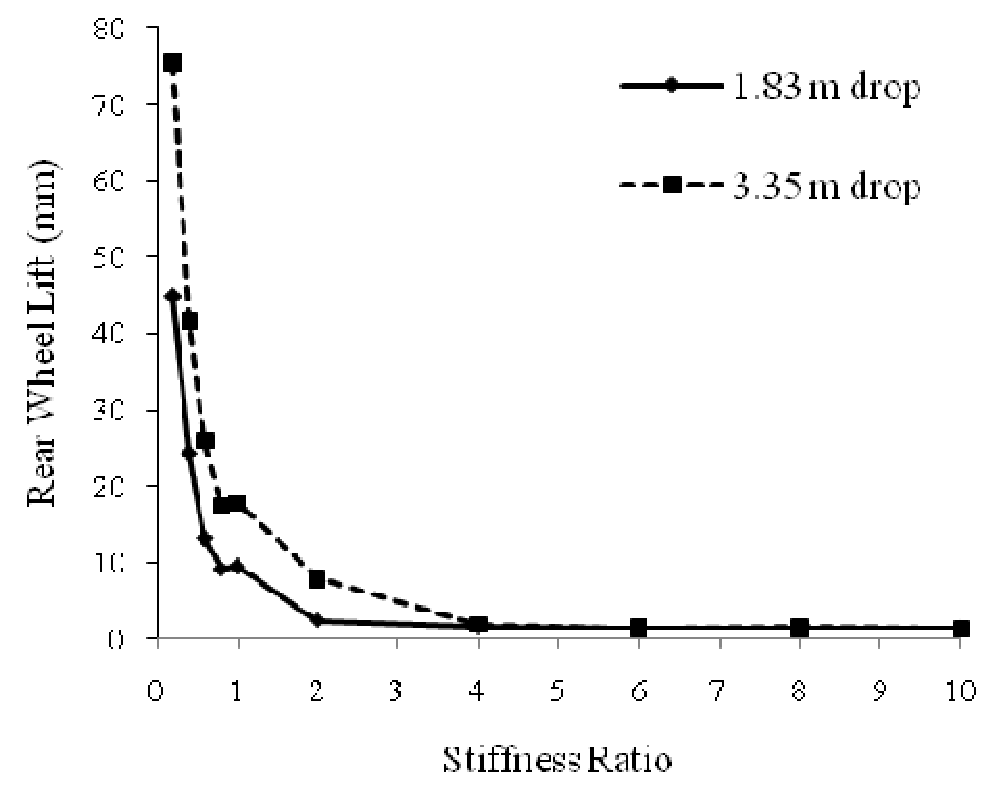

Fig. 22: Effect of the scissor lift structure stiffness on the rear wheel lifting height due to fall arrest forces 


\section{Chapter 5: Conclusion}

A dynamic model of a typical scissor lift has been developed using ADAMS ${ }^{\circledR}$. Using results from experimental tests, the scissor lift model was calibrated and validated. The scissor lift model's CG is nearly the same as the measured CG for the positions examined. Further, the scissor lift model's responses to a curb impact and depression simulation agree well with the experimental results of these tests. From the simulation of the considered scenarios, it was determined that an increase in the flexibility of the scissor lift generally reduces its stability. Although small increases in flexibility have minimal effects, large increases can drastically reduce its stability. Additionally, increasing the stiffness of the scissor lift model beyond the normal value improved its stability.

Increasing the stiffness of a new scissor lift could be a difficult task. Completely eliminating clearances in the joints would be impossible. However, proper maintenance and inspection of the scissor lift could prevent additional clearances in the joints from occurring. The design and manufacture of the pothole protection device could be critical in reducing tip-overs/rollovers under certain circumstances. The results suggest the pothole protection device to be as low to the ground as possible. In order to be effective, proper materials must be chosen for the pothole protection device so that it does not deform during impacts. 


\section{Chapter 6: Future Work}

Using the developed scissor lift model, additional hazardous scenarios such as driving off a curb, struck by an object, or exposure to combined loading may be examined. The effect of environmental factors such as wind on scissor lift stability could also be determined. The road surface roughness may also significantly affect the scissor lift's stability. Further model development could be achieved by incorporating a biodynamic human model with the scissor lift model, as shown in Fig. 21. This would lead to a better understanding of the effects of operator's actions on scissor lift stability. Since the dynamic responses of this model are similar to the actual lift's for the full height condition, the lumped parameter scissor lift model was considered sufficient in analyzing dynamic conditions at the full elevation. However, it is unknown whether the model will be valid at other lift heights. Additional testing will be necessary to further validate the model. Also, the flexibility of the lift could be more evenly distributed by replacing ideal revolute joints with imperfect joints. Last, feasibility studies involving the use outriggers, an active hydraulic actuator system, or other engineering controls to prevent tip-overs could be performed using the developed scissor lift model. 


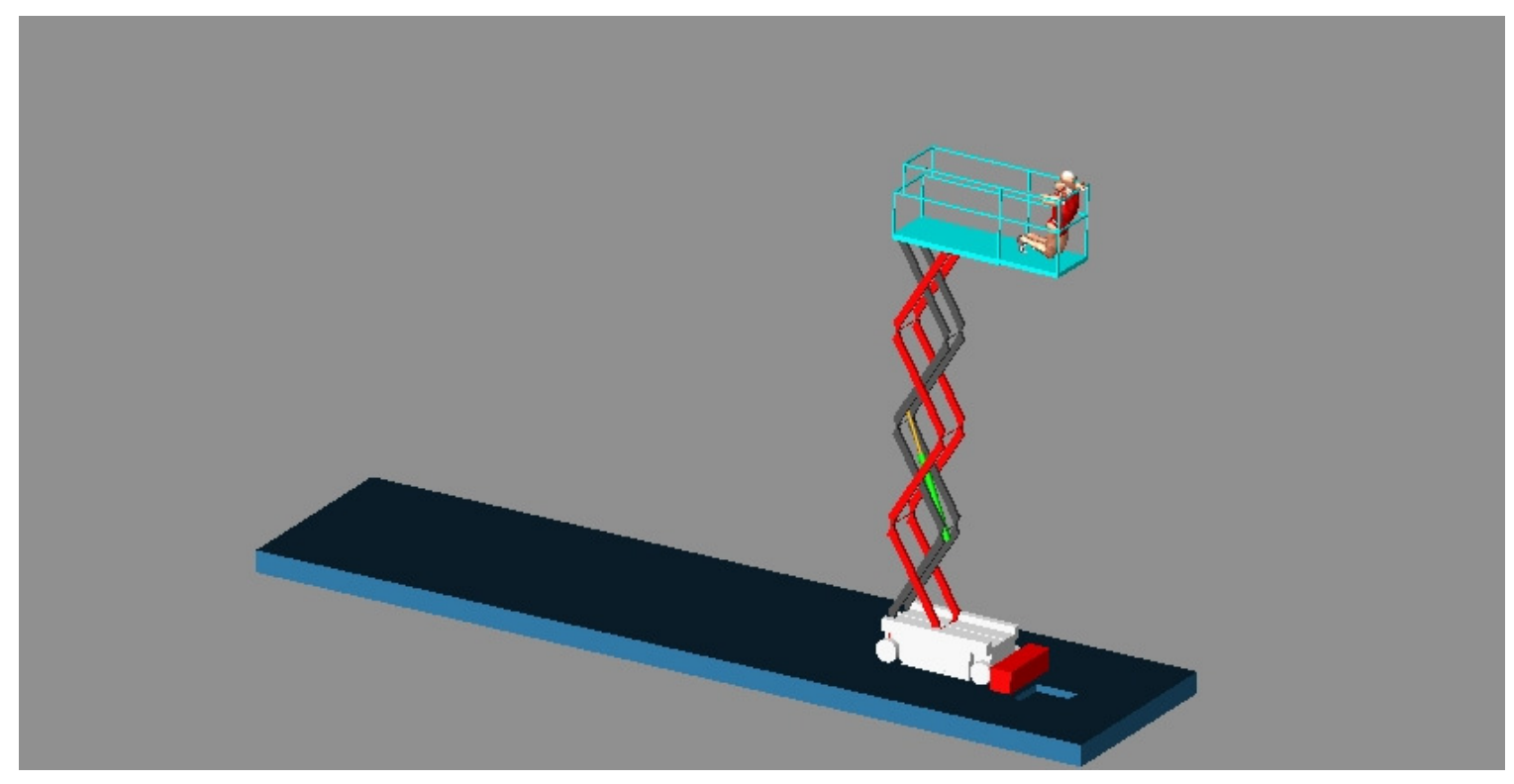

Fig. 23: Merging biodynamic model with scissor lift model 


\section{Chapter 7: References}

Abo-Shanab, R.F., and Sepehri, N. (2005). Tip-Over Stability of Manipulator-Like Mobile Hydraulic Machines. Journal of Dynamic Systems, Measurement, and Control, 127 (2), 295-301.

ANSI/SIA A92.6. (2006). Self-Propelled Elevating Aerial Work Platforms. American National Standards Institute (ANSI), New York, USA.

Bošnjak, S., Zrnić, N., and Dragović, B. (2009). Dynamic Response of Mobile Elevating Work Platform under Wind Excitation. Journal of Mechanical Engineering, 55 (2), 104-113.

Burkart, M.J., McCann, M., and Paine, D.M. (2004). Elevated Work Platforms and Scaffolding: Job Site Safety Manual. New York: The McGraw-Hill Companies, Inc.

Capitani, R., Masi, G., Meneghin, A., and Rosti, D. (2006). Handling analysis of a twowheeled vehicle using MSC.ADAMS/motorcycle, Vehicle System Dynamics, 44 supp., 698-707.

Flores, P., Ambrósio, J., Pimenta Claro, J.C., and Lankarani, H.M. (2008). Kinematics and Dynamics of Multibody Systems with Imperfect Joints. Berlin: Springer-Verlag Berlin Heidelberg.

ISO 16368 (2003): Mobile Elevating Work Platforms - Design Calculations, Safety Requirements and Test Methods. International Organization for Standardization, Geneva, Switzerland.

Kim, M.H., Oh, J.H., Lee, J.H., and Jeon, M.C. (2006). Development of rollover criteria based on a simple physical model of rollover event. International Journal of Automotive Technology, 7 (1), 51-59.

Knoll, L. (2002). Aerial Lift Accidents: Operator or Machine?. Occupational Health and Safety, 71 (9), 34-46.

McCann, M. (2003). Deaths in construction related to personnel lifts, 1992-1999. Journal of Safety Research, 34 (5), 507-514.

MSC Software Corporation. Adams 2008r1 manual. Santa Ana, California.

Nikravesh, P.E. (1988). Computer-Aided Analysis of Mechanical Systems. New Jersey: Prentice-Hall, Inc.

Pan, C.S., Hoskin, A., McCann, M., Lin, M., Fearn, K., and Keane, P. (2007). Aerial lift fall injuries: A surveillance and evaluation approach for targeting prevention activities. Journal of Safety Research, 38 (6), 617-625. 
Previati, G., Gobbi, M., and Mastinu, G. (2007). Farm tractor models for research and development purposes. Vehicle System Dynamics, 45 (1), 37-60.

Rao, S.S. (2004). Mechanical Vibrations. New Jersey: Pearson Education, Inc.

Ronaghi, M., Wu, J.Z., Pan, C.S., Harris, J.R., Welcome, D., Chiou, S.S., Boehler, B., and Dong, R.G. (2009). Scissor lift safety: An initiative to model static stability. Professional Safety, April, 43-48.

Yengst, C. (2002). Aerial work platforms no longer a bubble ready to burst - TrendLines. Diesel Progress North American Edition, 68 (10), 4.

Yengst, C. (2005). Things looking up for aerial work platforms. Diesel Progress North American Edition, 71 (1), 12. 